\title{
Infektionsprävention bei Tuberkulose - Empfehlungen des DZK
}

\section{Tuberculosis Infection Control - Recommendations of the DZK}

Autoren

Institute
R. Ziegler' ${ }^{1}$, H-M. Just ${ }^{1}$, S. Castell², R. Diel ${ }^{2}$, P. Gastmeier ${ }^{3}$, W. Haas ${ }^{4}$, B. Hauer ${ }^{4}$, G. Loytved ${ }^{5}$, M. Mielke ${ }^{4}$, I. Moser ${ }^{6}$, A. Nienhaus ${ }^{7}$, E. Richter ${ }^{8}$, H. Rüden ${ }^{9}$, S. Rüsch-Gerdes ${ }^{8}$, T. Schaberg ${ }^{10}$, N. Wischnewski ${ }^{11}$, R. Loddenkemper ${ }^{2}$

Die Institutsangaben sind am Ende des Beitrags gelistet.
Bibliografie

DOI http://dx.doi.org/

$10.1055 / \mathrm{s}-0031-1291582$

Online-Publikation: 31.1.2012

Pneumologie 2012; 66: 269-282

(c) Georg Thieme Verlag KG

Stuttgart · New York

ISSN 0934-8387

\section{Korrespondenzadresse}

Dr. med. Stefanie Castell

Deutsches Zentralkomitee zur Bekämpfung der Tuberkulose (DZK)

Stralauer Platz 34

10243 Berlin

info@dzk-tuberkulose.de

www.dzk-tuberkulose.de

\section{Zusammenfassung \\ $\nabla$}

In den letzten Jahren hat sich die epidemiologische Situation der Tuberkulose (TB) in Deutschland deutlich verbessert. Dennoch ist das Risiko für eine Tuberkuloseinfektion weiterhin für Personen erhöht, die häufig und/oder über längere Zeit und/oder intensiv ungeschützten Kontakt mit ansteckungsfähigen Tuberkulosekranken haben. Für die Infektionsprävention von besonderer Bedeutung sind die schnelle Diagnose, die frühe Einleitung einer effektiven Therapie und adäquate Hygienemaßnahmen.

Die vorliegenden Empfehlungen stellen Grundsätze der Infektionsprävention sowie spezifische Maßnahmen im Krankenhaus (räumliche Isolierung, Kriterien für deren Dauer und technische Anforderungen, Art des Mund-Nasen- bzw. Atemschutzes, Desinfektionsmaßnahmen, Entsorgung) dar. Spezifische Anforderungen im ambulanten medizinischen Bereich (Praxen), im häuslichen Bereich, beim Krankentransport und in Gemeinschaftseinrichtungen inkl. Justizvollzug werden dargestellt.

Abweichend von den bisherigen Empfehlungen ist das Schema der respiratorischen Schutzmaßnahmen vereinfacht worden. I.d.R. wird für Krankenhauspersonal und Besuch bei Kontakt mit ansteckungsfähigen Tuberkulosekranken ein Atemschutz, der die Kriterien einer FFP-2-Maske nach DINEN 149 erfüllt, und für Patienten ein MundNasen-Schutz (chirurgische Masken) in Anwesenheit anderer Personen bzw. bei Verlassen des Isolierzimmers empfohlen. Ergänzt wurde eine differenzierte Darstellung von Kriterien zur Isolierung und deren Dauer bei mikroskopisch positiver und nur kulturell positiver Lungentuberkulose.

\section{Abstract \\ $\nabla$}

The epidemiological situation of tuberculosis (TB) in Germany has improved considerably during the past few years. However, those in unprotected contact with infectious tuberculosis patients frequently and/or over longer periods of time and/ or intensively continue to have a higher risk for TB infection. Rapid diagnosis, prompt initiation of effective treatment, and adequate infection control measures are of particular importance to prevent infection.

The present recommendations depict the essentials of infection control as well as specific measures in the hospital (isolation, criteria for its duration and technical requirements, types of respiratory protection, disinfection measures, waste disposal). The specific requirements for outpatients (medical practice), at home, for ambulance services, and in congregate settings, including prisons, are also addressed.

Compared with the previous recommendations the pattern of respiratory protection measures has been simplified. As a rule, hospital staff and those visiting infectious tuberculosis patients are advised to wear respiratory protection that satisfies the criteria of FFP2-masks (DINEN 149), while patients should wear mouth-nose protectors (surgical masks) in the presence of others and outside the isolation room. A detailed depiction of criteria for isolation and its duration in smear positive and only culturally confirmed pulmonary tuberculosis has been added. 


\begin{tabular}{|l|l|}
\hline Inhaltsverzeichnis \\
\hline 1 & Einführung \\
\hline 2 & Epidemiologie und Infektionsrisiko \\
\hline 3 & Erreger und Erkrankung \\
\hline 3.1 & Erregerreservoir \\
3.2 & Infektionsweg \\
3.3 & Infektionsrisiko \\
3.4 & Erkrankung \\
\hline 3.5 & Diagnostik \\
\hline 3.6 & Meldepflicht \\
\hline 4 & Grundsätze der Infektionsprävention \\
\hline 5 & Maßnahmen im Krankenhaus \\
\hline 5.1 & Räumliche Isolierung und technische Maßnahmen der \\
\hline 5.2 & Infektionskontrolle \\
\hline 5.3 & Dauer der Isolierung \\
\hline 5.3 .1 & Mund-Nasen- und Atemschutz \\
\hline 5.3 .2 & Medizinisches Personal (Beschäftigte) \\
\hline 5.3 .3 & Besucher \\
\hline 5.4 & Schutzkittel und Schutzhandschuhe \\
\hline 5.5 & Desinfektionsmaßnahmen \\
\hline 5.5 .1 & Flächendesinfektion \\
\hline 5.5 .2 & Medizinprodukte \\
\hline 5.6 & Entsorgung \\
\hline 5.7 & Maßnahmen bei an Tuberkulose erkrankten Kindern \\
\hline 6 & Maßnahmen im ambulanten medizinischen Bereich \\
\hline 7 & (Praxen) \\
\hline 8 & Maßnahmen im häuslichen Bereich \\
\hline 9 & Maßnahmen beim Krankentransport \\
\hline 10 & Maßnahmen in Justizvollzugsanstalten \\
\hline
\end{tabular}

\begin{tabular}{|c|c|}
\hline ECDC & European Centre for Disease Prevention and Control \\
\hline FFP & $\begin{array}{l}\text { Filtering Face Pieces (Partikel-filtrierende Atem- } \\
\text { schutzmasken) }\end{array}$ \\
\hline DINEN & $\begin{array}{l}\text { Deutsches Institut für Normung e.V., Europäische } \\
\text { Norm }\end{array}$ \\
\hline IfSG & Infektionsschutzgesetz \\
\hline IGRA & Interferon- $\gamma$ Release Assay \\
\hline LTBI & Latente tuberkulöse Infektion \\
\hline MDR-TB & Multiresistente Tuberkulose \\
\hline MNS & Mund-Nasen-Schutz \\
\hline PCR & $\begin{array}{l}\text { Polymerase Chain Reaction (Polymerase-Ketten- } \\
\text { reaktion) }\end{array}$ \\
\hline RDG & Reinigungs- und Desinfektionsgeräte \\
\hline RKI & Robert Koch-Institut \\
\hline RLT-Anlage & Raumlufttechnische Anlage \\
\hline TB & Tuberkulose \\
\hline THT & Tuberkulinhauttest \\
\hline WHO & Weltgesundheitsorganisation \\
\hline XDR-TB & extensiv resistente Tuberkulose \\
\hline
\end{tabular}

\section{Einführung}

Die Tuberkulose gehört weltweit zusammen mit HIV/AIDS und Malaria zu den häufigsten Infektionskrankheiten. Laut Weltgesundheitsorganisation (WHO) erkrankten 2010 schätzungsweise 8,8 Millionen Menschen neu an Tuberkulose, für 1,5 Millionen Menschen war die Erkrankung tödlich. In einigen Regionen steigt die Zahl der jährlichen Neuerkrankungen immer noch an [1]. Hierfür sind neben demografischen Faktoren wie Bevölkerungs- wachstum, höhere Lebenserwartung und Migration insbesondere die Verbreitung der HIV-Infektion und der Medikamentenresistenzen verantwortlich [2,3].

Wesentliche Grundpfeiler einer erfolgreichen Tuberkulosekontrolle sind, neben der raschen Identifikation und adäquaten Behandlung der Tuberkulose, Hygienemaßnahmen zur Infektionsverhütung, deren Bedeutung weltweit gerade in den letzten Jahren vor dem Hintergrund der oben genannten Entwicklungen neu bewertet und verstärkt anerkannt wurden [4,5].

Die vorliegenden Empfehlungen stellen eine Aktualisierung der 1994 veröffentlichten Empfehlungen des Deutschen Zentralkomitees zur Bekämpfung der Tuberkulose (DZK) dar [6], sind auf Anregung des Deutschen Zentralkomitees zur Bekämpfung der Tuberkulose von einer Arbeitsgruppe erstellt worden und orientieren sich an aktuellen nationalen und internationalen Empfehlungen sowie an der Studienlage [4,7-15].

Ebenfalls Berücksichtigung finden die epidemiologische Situation, die in Deutschland gegebenen hohen hygienischen Standards und Rahmenbedingungen sowie Erfahrungen hinsichtlich der Maßnahmen, die sich in der Vergangenheit als wirksam zur Verhütung von Übertragungen erwiesen haben. Die vorliegenden Empfehlungen richten sich an alle Einrichtungen, in denen Personen mit (Verdacht auf) Tuberkulose betreut oder behandelt werden.

Da im Bereich Infektionskontrolle aktuell rege Studienaktivitäten zu verzeichnen sind, wird dem Leser empfohlen, sich über diese Empfehlungen hinaus fortlaufend in der Fachliteratur oder online - z. B. über das Robert Koch-Institut (RKI, www.rki.de), das Deutsche Zentralkomitee zur Bekämpfung der Tuberkulose (www.dzk-tuberkulose.de) oder das „Global Health Delivery Project“ (http://www.ghdonline.org) - zu informieren.

\section{Epidemiologie und Infektionsrisiko}

Für die Beurteilung des Infektionsrisikos bei Tuberkulose ist die Kenntnis der epidemiologischen Daten eine wichtige Grundlage. Deutschland gehört zu den Niedriginzidenzländern mit seit Jahren abnehmenden Zahlen an Neuerkrankungen. Im Jahr 2009 wurden 4.444 Fälle gemeldet, entsprechend einer Inzidenz von 5,4 pro 100000 Einwohner $^{1}$ [16].

Die Analyse der Meldedaten der letzten Jahre zeigt

- in Abhängigkeit vom Alter zum Teil eine deutlich höhere Erkrankungsrate bei Männern als bei Frauen sowie

- eine Altersverteilung mit zwei Erkrankungshäufungen, einmal in der Altersgruppe 20 - 29 Jahre, die vorwiegend dem Bevölkerungsanteil mit ausländischer Staatsangehörigkeit zugeordnet werden kann, und einen weiteren Gipfel im höheren Lebensalter (ab 69 Jahren).

Die Inzidenz der Tuberkulose bei ausländischen Staatsbürgern ist mehr als fünf Mal so hoch wie in der deutschen Bevölkerung, 45\% der Erkrankten sind im Ausland - vorwiegend in der Türkei und osteuropäischen Ländern - geboren. Hohe Infektions- und Erkrankungsinzidenzen finden sich bei Personen, die aus Hochprävalenzländern mit zum Teil schlechter medizinischer Infrastruktur, Armut, mangelhaften hygienischen Verhältnissen und hohen HIV-Infektionsraten stammen.

In Deutschland ist der Anteil multiresistenter Tuberkuloseerreger (MDR-Tuberkulose) mit ca. 2,1\% eher niedrig [16]. Es ist jedoch

\footnotetext{
${ }^{1}$ Aus Gründen der besseren Lesbarkeit wird stets nur die grammatikalisch männliche Form angegeben.
} 
Tab. 1 WHO-Definition der Medikamentenresistenz (modifiziert nach [17]).

\begin{tabular}{|ll|}
\hline Jegliche Resistenz & $\begin{array}{l}\text { Resistenz gegen mindestens ein antituberkulöses } \\
\text { (Erstrang-)Medikament }\end{array}$ \\
\hline Mono-Resistenz & $\begin{array}{l}\text { Resistenz gegen ein einziges antituberkulöses } \\
\text { Medikament }\end{array}$ \\
\hline Poly-Resistenz & $\begin{array}{l}\text { Resistenz gegen mehr als ein antituberkulöses } \\
\text { Medikament, jedoch nicht Isoniazid und Rifampicin } \\
\text { zusammen }\end{array}$ \\
\hline MDR-TB & $\begin{array}{l}\text { "multidrug-resistant tuberculosis“: mindestens } \\
\text { Resistenz gegen die zwei Erstrangmedikamente } \\
\text { Isoniazid und Rifampicin }\end{array}$ \\
\hline XDR-TB & $\begin{array}{l}\text { "extensively drug-resistant tuberculosis“: MDR-TB } \\
\text { plus Resistenz gegen eines der Fluorochinolone } \\
\text { und mindestens eines der injizierbaren Zweitrang- } \\
\text { medikamente (Amikacin, Capreomycin, Kanamycin) }\end{array}$ \\
\hline
\end{tabular}

nicht auszuschließen, dass sich die weltweite Entwicklung mit einer zeitlichen Verzögerung auch in Deutschland widerspiegeln wird. Bezüglich der Definition der Resistenzen siehe $\bullet$ Tab. 1.

Nach Schätzungen der WHO beträgt weltweit der durchschnittliche Anteil der MDR-Tuberkulose an allen neuen Tuberkulosefällen etwa 3,3\% [18], das entspricht etwa einer halben Million Neuerkrankten jährlich. XDR-Tuberkulosefälle wurden bislang aus 69 Ländern berichtet (Stand 3 /2011) [18], darunter auch 15 EU-Länder $[1,19,20]$. XDR-Tuberkulosepatienten machen schätzungsweise 5,4\% der weltweiten MDR-Tuberkulosen aus [19]. Vereinzelt wurden bisher Fälle von Tuberkuloseerkrankungen gemeldet, die durch Erreger verursacht wurden, die gegen alle getesteten Antituberkulotika resistent sind [21].

Risikofaktoren für das Vorliegen einer Tuberkulose, die durch Erreger mit Resistenz gegen antituberkulöse Arzneimittel verursacht ist ${ }^{2}$, sind vor allem

- eine vorangegangene nicht effektive antituberkulöse Behandlung oder ein Therapieversagen,

- der Kontakt mit einem resistenten Tuberkulosefall und

- die Herkunft aus einem Land mit hoher MDR-TB-Prävalenz [2]. Die Therapieerfolgsraten sind bei Vorliegen einer Medikamentenresistenz, insbesondere bei komplexeren Resistenzen, in der Regel deutlich geringer als für Tuberkulosepatienten mit sensiblen Erregern [2].

Bezüglich der aktuellen epidemiologischen Situation in Deutschland wird auf die regelmäßigen Publikationen des Robert KochInstituts verwiesen (www.rki.de). Weiterführende Informationen zur Tuberkulosesituation in Europa und in der Welt sowie zu den Resistenzraten in anderen Herkunftsländern können den aktuellen Publikationen des European Centre for Disease Prevention and Control (ECDC, www.ecdc.europa.eu) und der Weltgesundheitsorganisation (WHO, www.who.int/tb) entnommen werden.

Angesichts der derzeitigen epidemiologischen Situation ist in Deutschland das Risiko für den Erwerb einer Tuberkuloseinfektion für die Allgemeinbevölkerung gering. Erhöht ist dieses allerdings für Personen, die häufig und/oder über längere Zeit und/ oder intensiv ungeschützten Kontakt mit - vor allem noch nicht diagnostizierten und nicht therapierten - ansteckungsfähigen Tuberkulosekranken haben, wie dies für Familienangehörige und enge Kontaktpersonen, medizinisches Personal und Mitpatienten zutreffen kann. Für Beschäftigte im Gesundheitswesen kann auch in Regionen mit niedriger Tuberkuloseprävalenz eine

\footnotetext{
${ }^{2}$ Im Folgenden resistente Tuberkulose genannt.
}

erhöhte Gefährdung vorliegen, sich mit dem Tuberkuloseerreger zu infizieren [22]. Studien, basierend auf Tuberkulinkonversionsraten, und Prävalenzstudien zu aktiver, d.h. behandlungsbedürftiger Tuberkulose, zusammen mit neueren Ergebnissen molekular-epidemiologischer Studien (Fingerprinting) zeigen für medizinisches Personal ein nach Berufsgruppe, Fachdisziplin und Tätigkeitsbereich unterschiedliches Risiko [23]. In medizinischen Einrichtungen sind bestimmte diagnostische und therapeutische Tätigkeiten, die an ansteckungsfähigen Tuberkulosepatienten insbesondere vor der Diagnosestellung durchgeführt werden, mit einem erhöhten Übertragungsrisiko verbunden. Dazu gehören Tätigkeiten mit möglichem Kontakt zu erregerhaltigen Aerosolen wie bei der

- Sputuminduktion (Inhalation),

- Bronchoskopie,

Intubation,

- Beatmung (beim Absaugen),

- Reanimation.

Weitere Tätigkeitsbereiche mit erhöhtem Expositionsrisiko sind die Pathologie und bakteriologische Laboratorien [23 - 26]. Auch für Personen, die in der Betreuung von Risikogruppen (zum Beispiel Obdachlose, Drogenabhängige, Häftlinge) tätig sind, konnte zum Teil ein erhöhtes Infektionsrisiko nachgewiesen werden [27, 28]. Ein erhöhtes Risiko findet sich dabei insbesondere in Situationen, in denen mit nicht diagnostizierten und daher nicht behandelten infektiösen Tuberkulosepatienten umgegangen wird, wenn keine gezielten Infektionsschutzmaßnahmen ergriffen wurden [29]. Die Ergebnisse aus Studien mit dem Tuberkulinhauttest (THT) werden durch neuere Untersuchungen mittels Interferon-Gamma-Tests (Interferon Gamma Release Assay, kurz IGRA) zum Beispiel zur Infektionsprävalenz im deutschen Gesundheitswesen bestätigt. Unter Personal, das beruflich gegenüber Tuberkulosekranken exponiert war, lag die Prävalenz der latenten tuberkulösen Infektion (LTBI) bei 9,6\% [30], wobei allerdings vergleichbare Zahlen aus der Bevölkerung fehlen. Eine erhöhte Infektionsprävalenz konnte insbesondere für in der Geriatrie Tätige gezeigt werden [31]. Im Rahmen der Beweiserleichterung wird für die Anerkennung der Tuberkulose als Berufskrankheit eine erhöhte Gefährdung unter anderem für Beschäftigte von Lungenfachpraxen, Laboren, die Sputumproben untersuchen, Notaufnahmen, Rettungsdienste, Infektionsstationen, Pathologie, Rechtsmedizin, Geriatrie und Altenpflege sowie bei der Betreuung von Hochrisikogruppen wie Obdachlose, IVDrogenabhängige, Alkoholiker und Migranten aus Hochprävalenzländern angenommen [32].

\section{Erreger und Erkrankung}

\subsection{Erregerreservoir}

Als Erreger der Tuberkulose beim Menschen dominiert die Spezies Mycobacterium tuberculosis. In Mitteleuropa ist der an Tuberkulose erkrankte Mensch derzeit das einzig epidemiologisch relevante Erregerreservoir, die Tuberkulose wird daher praktisch nur von Mensch zu Mensch übertragen.

Aufgrund staatlicher Maßnahmen ist die Rindertuberkulose durch Mycobacterium bovis in den meisten europäischen Ländern unter Kontrolle. Auch in Deutschland war die Rindertuberkulose früher für 10-30\% der Tuberkulosen beim Menschen verantwortlich. In Deutschland liegt der Anteil an M. bovis ssp. bovis Stämmen unter den kulturell positiven Tuberkulosefällen mit Speziesdifferenzierung unter $2 \%$, wobei hier vornehmlich Reak- 
tivierungen angenommen werden [16]. Erkrankungen mit anderen Erregern des M. tuberculosis-Komplexes kommen nur in Einzelfällen vor $[16,33]$.

Länder, in denen mindestens 99,9\% der Rinderbestände frei von Tuberkulose sind, gelten als „amtlich frei von Rindertuberkulose“. Dies ist in vielen (z. B. Deutschland, Österreich, Schweiz, Niederlande), jedoch nicht allen Ländern Europas der Fall. Vor der Wiedervereinigung im Jahr 1990 waren West- und Ostdeutschland seit Anfang der 60er- bzw. Ende der 70er-Jahre amtlich Rindertuberkulose-frei, das vereinigte Deutschland erhielt diesen Status erneut durch die EU-Entscheidung vom 17.12.1996.

M. bovis, $M$. bovis ssp. caprae, auch $M$. tuberculosis spielen als Erreger der Tuberkulose bei verschiedenen Wildtieren (Rotwild, Wildschwein, Dachs, Büffel) eine Rolle. Selten treten auch Erkrankungen beim Haustier bzw. in Zoopopulationen auf, wobei in Einzelfällen auch Übertragungen vom Tier auf den Menschen in der Literatur beschrieben sind [33-38]. Nach dem Tierseuchengesetz $\S 9$ [40] und der Verordnung über anzeigepflichtige Tierseuchen $§ 1$ [41] besteht eine Anzeigepflicht für Tuberkulose der Rinder, hervorgerufen durch $M$. bovis und $M$. bovis ssp. caprae, sowie eine Meldepflicht für Tuberkulose mit M. tuberculosis-Komplex bei verschiedenen weiteren Tierarten an die nach Landesrecht zuständige Behörde (Anlage zu §1 nach der Verordnung für meldepflichtige Tiererkrankungen [42]). Impf- und Heilversuche sind beim Rind verboten.

Je nach Risikoeinschätzung sollte eine Infektion bei Personen, welche tuberkulosekranke Tiere betreuen, ausgeschlossen werden. Bei Befall von Tierbeständen ist die Durchführung von Umgebungsuntersuchungen bei exponierten Personen in Zusammenarbeit von Veterinäramt und Gesundheitsamt fachlich geboten. Gesetzliche Regelungen hierzu sind nicht vorhanden.

Tiere, die mit einem an infektiöser Tuberkulose Erkrankten in enger Gemeinschaft leben, können infiziert werden [43,44], sollten daher beobachtet werden und bei Auftreten von Krankheitssymptomen auf Tuberkulose untersucht werden.

$\mathrm{Zu}$ beachten ist hierbei, dass eine valide immunologische Diagnostik (latente tuberkulöse Infektion) mit Ausnahme des Rindes bei den meisten Tierarten bisher nicht möglich ist [38]. Beim kleinen Haustier (Hund, Katze etc.) kann - falls ein Krankheitsverdacht besteht - die Diagnostik einer aktiven Tuberkulose mittels bildgebender Verfahren erfolgen. Die bakteriologische Diagnostik ante mortem kann bei Manifestation in der Lunge mittels Bronchiallavage versucht werden. Für das weitere Vorgehen bei Feststellung einer Erkrankung fehlen allerdings gesetzliche Vorschriften. Eine gut wirksame antituberkulöse Therapie ist beim Tier nicht evaluiert [38].

Insgesamt ist die Wahrscheinlichkeit der Übertragung vom Tier auf den Menschen durch direkte Exposition und infektiöse Lebensmittel jedoch in Ländern mit hohem Lebens- und Hygienestandard als eher gering einzustufen [39].

\subsection{Infektionsweg}

Der epidemiologisch bedeutendste Übertragungsweg ist die aerogene Übertragung mittels kleinster erregerhaltiger Tröpfchen des Bronchialsekretes („droplet nuclei“, $<5 \mu \mathrm{m}$ ), die vom Erkrankten beim Husten, Niesen, Sprechen oder Singen freigesetzt und von Kontaktpersonen inhaliert werden können. Vehikel der Erreger sind kleinste, rasch eintrocknende Tröpfchen, die ein umso höheres Infektionspotential haben, je geringer ihr Durchmesser ist. Nur die kleinsten Tröpfchenkerne können genügend lang in der Luft schweben und so Aerosole bilden, die mit dem Atemstrom bis in die Peripherie der Lunge gelangen und dort eine Infektion verursachen können. Größere Tröpfchenkerne sedimentieren dagegen rascher und können von den Selbstreinigungsmechanismen der Atemwege eliminiert werden. Ihre Ansteckungsfähigkeit ist daher eher gering. Trotz theoretisch langer Überlebensfähigkeit (Wochen bis Monate) von sedimentierten, also in eingetrocknetem Sputum auf Oberflächen eingeschlossenen Erregern werden diese nicht als relevante Infektionsquelle erachtet [45]. Hinsichtlich der Desinfektion wird allerdings auf potenzielle Wirkungslücken von Desinfektionsmitteln hingewiesen. Deshalb sollen zur gezielten Desinfektion nur ausdrücklich auf Wirksamkeit gegen Mykobakterien begutachtete Präparate verwendet werden. Eine Hilfestellung kann die Desinfektionsmittelliste des VAH (Verbund für Angewandte Hygiene e.V.) - zu beziehen über den MHP-Verlag - darstellen [46].

Für die Praxis bedeutet dies, dass an Tuberkulose der Atmungsorgane (Lunge, Bronchien) Erkrankte die Krankheit dann übertragen können, wenn ihr ausgehustetes Bronchialsekret in ausreichender Menge vitale Erreger enthält und diese durch Husten als Tröpfchen respektive dem sich daraus entwickelnden Aerosol in die Umgebungsluft gelangen. Auch bei extrapulmonaler Tuberkulose kann es zu einer Ausscheidung von Tuberkulosebakterien kommen, so z. B. bei der Urogenitaltuberkulose mit dem Urin, bei Perforation und/oder Fistelung von Lymphknoten bzw. Herden einer Organtuberkulose mit dem Eiter bzw. über erregerhaltiges Wundsekret $[47,48]$. Wenn von einer niedrigen Erregerkonzentration auszugehen ist und es nicht zur Aerosolbildung kommt, ist die Wahrscheinlichkeit der Übertragung als gering anzusehen. In seltenen Fällen kann eine Infektion auch durch Inokulation des Erregers auf perkutanem Weg erfolgen, wenn eine Verletzung mit einem kontaminierten Gegenstand stattgefunden hat [49].

\subsection{Infektionsrisiko}

Das Risiko einer Infektion mit Erregern der Tuberkulose hängt von den Umständen der Exposition (Konzentration der Bakterien in der Umgebungsluft, Virulenz der Erreger, der Expositionsdauer und -intensität) ab [50]. Das größte Risiko für ihre Umgebung stellen Patienten mit einer ansteckungsfähigen Tuberkulose der Atmungsorgane dar, bei denen die Erkrankung noch nicht diagnostiziert wurde und daher noch nicht therapiert wird. Die Ansteckungsfähigkeit ist am höchsten, solange säurefeste Stäbchen mikroskopisch, als Zeichen einer hohen Keimzahl, in respiratorischen Sekreten nachweisbar sind (Nachweisgrenze 103-104 Bakterien pro $\mathrm{ml}$ ). Die Ansteckungsfähigkeit von Patienten, bei denen lediglich ein kultureller oder molekularbiologischer Keimnachweis gelingt, ist demgegenüber deutlich geringer [51,52]. Studien zeigen jedoch, dass bis zu knapp 30\% der Tuberkulosefälle von mikroskopisch negativen Indexfällen verursacht werden [53 - 55]. Grundsätzlich kann es also auch zu Übertragungen bei bakteriologisch bestätigtem, aber mikroskopisch negativem Befund kommen. Deshalb können Patienten auch dann infektiös sein, wenn lediglich ein molekularbiologischer (PCR) oder kultureller Erregernachweis erfolgt [50]. Da wenige Tage nach Beginn einer adäquaten Tuberkulose-Therapie die Konzentration sowie die Vitalität der Erreger im Sputum abnimmt, kann man davon ausgehen, dass Patienten, die eine deutliche klinische Besserung - vor allem der Hustensymptomatik - zeigen und bei denen eine Erkrankung mit einem sensiblen Erregerstamm besteht, in der Regel innerhalb von 2-3 Wochen nach Therapiebeginn nicht mehr ansteckend sind [56-58]. Bei einem ausgedehnten pulmonalen Befund, insbesondere bei Kavernenbildung und/oder bei Erkrankungen durch resistente Erreger, kann die Ansteckungs- 
fähigkeit deutlich länger bestehen und muss individuell unter Berücksichtigung aller relevanten Faktoren (Erregerdichte im Sputum, Hustensymptomatik, Ausdehnung des Röntgenbefundes, Möglichkeit der Infektion mit einem resistenten Bakterienstamm, Patienten-Compliance) eingeschätzt werden [59]. Bei der Beurteilung der Ansteckungsfähigkeit des Einzelfalls sollte bedacht werden, dass selbst bei adäquater Therapie bis zu $10 \%$ der Patienten mit initial mikroskopisch positivem Sputumbefund noch nach zwölf Wochen in der Kultur positiv sein können [58] (siehe auch Kapitel 5.2).

Damit eine Übertragung stattfinden kann, ist in aller Regel eine lang dauernde oder intensive, also direkte Exposition in einem ungenügend gelüfteten Raum notwendig. Als infektionsgefährdet gelten daher Kontaktpersonen,

- die mit dem ansteckungsfähigen Kranken in derselben Wohnung, Zelle (Justizvollzug) oder in sonstigen Räumen gelebt haben oder intime Kontakte hatten,

- ebenso Personen mit intensivem - auch einmaligem Kontakt, bei dem erregerhaltiges Aerosol eingeatmet wurde (z.B. bei Reanimation).

Zu Tuberkulosepatienten mit mikroskopisch positivem Sputumausstrich muss in der Regel während des Infektionszeitraumes kumulativ mindestens 8 Stunden Kontakt in geschlossenen Räumen bestanden haben, bevor von einem nennenswerten Infektionsrisiko ausgegangen werden kann [50,60]. Hingegen ist ein relevantes Übertragungsrisiko von einem Indexfall mit nur kulturell und/oder molekularbiologisch geführtem Erregernachweis i.d.R. erst nach mindestens insgesamt 40-stündigem Kontakt zu erwarten [50, 61]. Dies schließt jedoch nicht aus, dass bei intensiven einmaligen Kontakten eine Ansteckung erfolgen kann [23]. In allen anderen Fällen ist entscheidend, ob bei der Kontaktperson ein individuell erhöhtes Risiko für eine Tuberkuloseinfektion beziehungsweise für eine Progression von einer Infektion zu einer behandlungsbedürftigen Erkrankung vorliegt [50]. Außerhalb geschlossener Räume ist das Ansteckungsrisiko generell gering.

Es gibt wenige Hinweise für eine Ansteckung während Flugreisen [60]. Bisher wurde kein Fall einer aktiven Tuberkuloseerkrankung nach Übertragung während einer Flugreise berichtet [62]. Für Langstreckenreisen in Bus und Bahn ist die Datenlage noch unbefriedigend [63].

\subsection{Erkrankung}

Bei der Tuberkulose können im Gegensatz zu vielen anderen Infektionskrankheiten lange Zeitspannen von wenigen Wochen bis Jahrzehnten zwischen der Infektion mit dem Tuberkuloseerreger und dem Auftreten der behandlungsbedürftigen Erkrankung vergehen. Das Progressionsrisiko, also das Risiko nach Infektion zu erkranken, ist in den ersten beiden Jahren nach der Ansteckung am höchsten. Bis zu 17\% der IGRA-positiven Erwachsenen entwickeln eine aktive Tuberkulose [64,65]. Höhergradig immungeschwächte Menschen haben dagegen ein deutlich größeres Erkrankungsrisiko [66]. Im Kindesalter ist das Erkrankungsrisiko in Abhängigkeit vom Alter auf mehr als $40 \%$ erhöht $[65,67]$.

Die HIV-Infektion gilt als größter Risikofaktor für eine Progression einer latenten tuberkulösen Infektion zu einer aktiven Tuberkulose. Weitere Risikofaktoren sind Diabetes mellitus, Silikose, Niereninsuffizienz, immunsuppressive Therapien (z.B. TNF-alpha-Blockade bei chronisch entzündlichen, immunmodulierenden Erkrankungen, z.B. des rheumatischen Formenkreises, Psoriasis und M. Crohn; iatrogene Immunsuppression bei Transplantatempfängern), hämatologische maligne Grunderkrankung, erhöhter Alkoholkonsum, Rauchen sowie Drogenabhängigkeit $[50,68-71]$.

\subsection{Diagnostik}

Die Tuberkulosediagnostik beruht auf dem Nachweis eines Erregers des Mycobacterium tuberculosis-Komplexes in Sputum, Bronchialsekret (ggf. Magensaft) oder anderen erregerhaltigen Materialien erkrankter Organsysteme. Dieser Nachweis erfolgt durch die mikroskopische Untersuchung nach geeigneten Färbeverfahren, durch kulturellen Nachweis in verschiedenen festen und flüssigen Nährmedien oder durch Nukleinsäureamplifikationstechniken wie der PCR (Polymerase chain reaction) [72]. Eine Empfindlichkeitsprüfung des kulturell angezüchteten Erregers auf Erstrang-Antituberkulotika und bei Vorliegen von Medikamentenresistenzen auf Zweitrang-Antituberkulotika gehört heute in Deutschland zur Standarddiagnostik, dauert jedoch ein bis drei Wochen. Die Testung auf Zweitrang-Antituberkulotika wird nur in Speziallaboratorien durchgeführt. Darüber hinaus gibt es inzwischen die Möglichkeit, bereits aus der Patientenprobe (z. B. Sputum) innerhalb weniger Stunden eine molekularbiologische Resistenzbestimmung für einzelne Antituberkulotika durchzuführen (z.B. GeneXpert ${ }^{\circledR}$, Cepheid: Rifampicin; GenoType ${ }^{\circledR}$ MTBDRplus/sl, HAIN Lifescience: Rifampicin, Isoniazid, Ethambutol, Amikacin, Capreomycin, Fluorchinolone) [73,74]. Die beiden Streifenhybridisierungsverfahren (GenoType ${ }^{\circledR}$ ) sind allerdings nur bei mikroskopisch positiven Materialien einsetzbar. Da mit sämtlichen molekularbiologischen Methoden nicht alle Resistenzen erkannt werden und darüber hinaus nicht alle relevanten Medikamente getestet werden können, kann auf die Durchführung phänotypischer Verfahren der Resistenztestung nicht verzichtet werden.

Für Kontaktpersonen stehen mit dem Tuberkulin-Hauttest wie auch mit den spezifischeren Interferon- $\gamma$-Tests (Bestimmung der Freisetzung von Gamma-Interferon durch in vitro stimulierte TLymphozyten) Untersuchungsmethoden zur Verfügung, um eine eventuelle Infektion nachzuweisen [50,75]. Der Nachweis der Sensibilisierung gegenüber Tuberkulose-Antigenen ist ein indirekter Hinweis für eine immunologische Auseinandersetzung mit M. tuberculosis. Sowohl IGRA als auch THT können jedoch nicht zwischen latenter Infektion und aktiver Erkrankung unterscheiden und sind daher nicht geeignet, in klinisch oder radiologisch verdächtigen Fällen eine aktive Tuberkulose sicher zu bestätigen oder auszuschließen [76,77]. Für tiefer gehende Erläuterungen zu Umgebungsuntersuchungen sei auf die entsprechenden Empfehlungen des DZK verwiesen [50].

\subsection{Meldepflicht}

Ärzte sind nach §6 Abs. 1 Infektionsschutzgesetz (IfSG) zur Meldung verpflichtet, wenn sie eine Erkrankung oder den Tod an behandlungsbedürftiger Tuberkulose feststellen. Meldepflicht besteht unabhängig vom bakteriologischen Befund grundsätzlich, wenn die Indikation zur Durchführung einer vollständigen Antituberkulotika-Therapie gestellt wird bzw. bei post-mortem diagnostizierten Fällen zu Lebzeiten gestellt worden wäre. Nach §7 besteht für mikrobiologische Laboratorien die Meldepflicht für den mikroskopischen Nachweis von säurefesten Stäbchen im Sputum, für den direkten Erregernachweis (alle zum M. tuberculosis-Komplex gehörigen Spezies außer BCG, d.h. z.Zt. M. tuberculosis, M. bovis (ssp. bovis und ssp. caprae), M. africanum, M. microti, M. canettii, M. pinnipedii) sowie für das nachfolgende Ergebnis der Resistenzbestimmung. Pathologen sind nach $\S 8$ Abs. 1 Nr.3 IfSG zur Meldung verpflichtet, wenn ein Befund er- 
hoben wird, der sicher oder mit hoher Wahrscheinlichkeit auf das Vorliegen einer Tuberkulose schließen lässt. Darüber hinaus ist bei Entlassung aus dem Krankenhaus nach $§ 9$ Abs. 1 Nr.12 IfSG dem Gesundheitsamt der Aufenthaltsort des Patienten zu melden. Falls Patienten die Behandlung abbrechen (Meldepflicht nach $\S 6$ Abs.2), wird bei nicht-infektiösen Tuberkulosen eine Überwachung des Infektionsstatus und der Krankheitsprogredienz mittels regelmäßiger Thoraxröntgen- und Sputumuntersuchung (§29 IfSG) durchgeführt. Bei infektiösen Tuberkulosepatienten kann bei Therapieabbruch oder ungenügender Compliance nach §30 IfSG eine sogenannte zwangsweise Absonderung (Quarantäne) richterlich angeordnet werden $[78,79]$. Entsprechende Einrichtungen befinden sich beispielsweise in Parsberg und in Bad Lippspringe.

\section{Grundsätze der Infektionsprävention}

Sämtliche Präventionsmaßnahmen bei ansteckungsfähiger Tuberkulose zielen darauf ab, das Risiko einer Infektion bei Kontaktpersonen zu minimieren bzw. bei bereits erfolgter Exposition infizierte Personen zu erfassen.

Hierfür sind von besonderer Bedeutung:

- die schnelle Diagnose, d.h. das schnelle Auffinden von erkrankten und insbesondere von ansteckungsfähigen Personen,

- die frühe Einleitung einer wirksamen Therapie mit konsequenter Durchführung,

$\checkmark$ adäquate Hygienemaßnahmen.

Ein effizienter Infektionsschutz kann nur erreicht werden, wenn diese Maßnahmen als Einheit gesehen werden und ihre Umsetzung konsequent erfolgt. Aufgrund der Datenlage ist es schwierig, den Stellenwert der einzelnen Maßnahmen zu definieren. Die größte Bedeutung haben die organisatorisch-administrativen Maßnahmen im Sinne von schneller Diagnosestellung, wirksamer Therapie und räumlicher Isolierung, gefolgt von technischen und persönlichen Schutzmaßnahmen [29].

Die BCG-Impfung gegen Tuberkulose wird von der Ständigen Impfkommission (STIKO) am Robert Koch-Institut seit 1998 nicht mehr empfohlen. Zu den Themen Diagnostik und Therapie der Tuberkulose sowie Umgebungsuntersuchungen bei Tuberkulose wird auf weiterführende Literatur und die entsprechenden Empfehlungen des DZK verwiesen [50,72,80-83].

In den folgenden Kapiteln wird auf Präventionsmaßnahmen eingegangen, die in Bereichen Anwendung finden sollen, in denen Patienten mit einer ansteckungsfähigen Tuberkulose betreut werden. Je nach Infektionsrisiko sind dabei unterschiedliche Maßnahmen in stationären und ambulanten medizinischen Einrichtungen, im häuslichen Bereich, beim Krankentransport oder in Gemeinschaftseinrichtungen, insbesondere im Justizvollzug, notwendig.

\section{Maßnahmen im Krankenhaus}

$\nabla$

In Niedriginzidenzländern wie Deutschland, in denen das Krankheitsbild der Tuberkulose für Mediziner inzwischen eher eine Seltenheit darstellt, wird - auch vor dem Hintergrund des Auftretens möglicher Resistenzen und unerwünschter Arzneimittelwirkungen sowie der oftmals bestehenden Komorbidität - die Initialbehandlung einer Tuberkulose häufig unter stationären Bedingungen begonnen. 2009 wurde bei 71,2\% der gemeldeten Fälle mit entsprechenden Informationen ein Klinikaufenthalt angegeben [16]. Dies erleichtert häufig die Diagnostik (insbesondere differenzialdiagnostisch schwieriger Fälle), erlaubt eine zuverlässige Isolierung, eine rasche Therapieeinleitung mit überwachter Medikamenteneinnahme, die rechtzeitige Erfassung sowie Therapie von unerwünschten Arzneimittelwirkungen und die Behandlung von Begleit- oder Grunderkrankungen [80].

Um die Übertragung des Tuberkuloseerregers von ansteckungsfähigen Patienten auf medizinisches Personal, Mitpatienten und Besucher zu verhindern, sind bestimmte Verhaltensregeln einzuhalten. Diese sollen einerseits die Freisetzung infektiöser Aerosole und andererseits die Inhalation von Erregern verhindern. Da die zuverlässige Kooperation der Patienten ein wichtiger Bestandteil aller Präventionsmaßnahmen ist, müssen diese über ihre Krankheit verständlich informiert werden und den Sinn aller Maßnahmen verstehen, welche von ihnen, vom betreuenden medizinischen Personal und auch von den Besuchern befolgt werden müssen. Hilfreich haben sich hierfür schriftliche Informationsblätter für Patienten und Angehörige erwiesen. Sie sollten - möglichst in der jeweiligen Muttersprache - auf den entsprechenden Stationen vorhanden sein (Patientenbroschüre, z. B. über das DZK erhältlich). Der Besucherkreis ist auf die wichtigsten Bezugspersonen (keine Kinder unter fünf Jahren, fünf- bis 14-jährige nur in begründeten Ausnahmen) zu beschränken.

Im Folgenden werden Maßnahmen aufgeführt, die sich in der Infektionsprävention bewährt haben. Da die wissenschaftliche Beurteilung der einzelnen Maßnahmen sehr schwierig ist, gibt es für deren Effektivität wenig oder keine Evidenz, weshalb auf eine Kategorisierung nach den üblichen Evidenzkriterien verzichtet wird. Damit wird auch verständlich, warum aktuelle Empfehlungen verschiedener, auch internationaler Fachgesellschaften oder Institutionen (USA, Schweiz, England) den Stellenwert einzelner Hygienemaßnahmen unterschiedlich beurteilen [11-13]. Übereinstimmend sehen aber alle Empfehlungen den Schwerpunkt der Präventionsstrategien in der Früherkennung von an Tuberkulose erkrankten Personen, einer schnellen und effektiven Therapie und der konsequenten Anwendung von bewährten Schutzmaßnahmen [14].

\subsection{Räumliche Isolierung und technische Maßnahmen der Infektionskontrolle}

Stationär betreute Patienten mit einer vermuteten oder bestätigten Tuberkulose sind bis zum Ausschluss ihrer Ansteckungsfähigkeit bzw. für die Dauer der Ansteckungsfähigkeit in dafür geeigneten Räumen mit eigener Nasszelle zu isolieren. Dies betrifft vornehmlich Patienten mit einer ansteckungsfähigen Lungentuberkulose, bei denen mikroskopisch ein Erregernachweis aus Atemwegssekreten erfolgt ist. Fälle mit dreimalig negativer Sputummikroskopie unterliegen hinsichtlich einer Isolierung der ärztlichen Abwägung, in welche die Befunde der Bildgebung (Vorliegen von Kavernen), Hustensymptomatik, BronchoskopieErgebnisse, Ergebnisse eines molekularbiologischen Erregernachweises (z.B. PCR), Vorliegen von Folgefällen und der Verdacht auf das Vorhandensein resistenter Erreger einfließen sollen (siehe $\bullet$ Abb. 1).

In Fällen, in denen eine pulmonale Tuberkulose differenzialdiagnostisch nicht sicher ausgeschlossen werden kann, jedoch aufgrund der gesamten Befundkonstellation keine antituberkulöse Therapie eingeleitet wird, muss individuell entschieden werden, ob eine Isolierung bis zur Erhärtung der vermuteten Diagnose (klinisches Ansprechen auf die gewählte Behandlung) notwendig ist. Auch hier sollten die im Algorithmus genannten Kriterien bei negativer Sputummikroskopie berücksichtigt werden ( $\bullet$ Abb.1). 


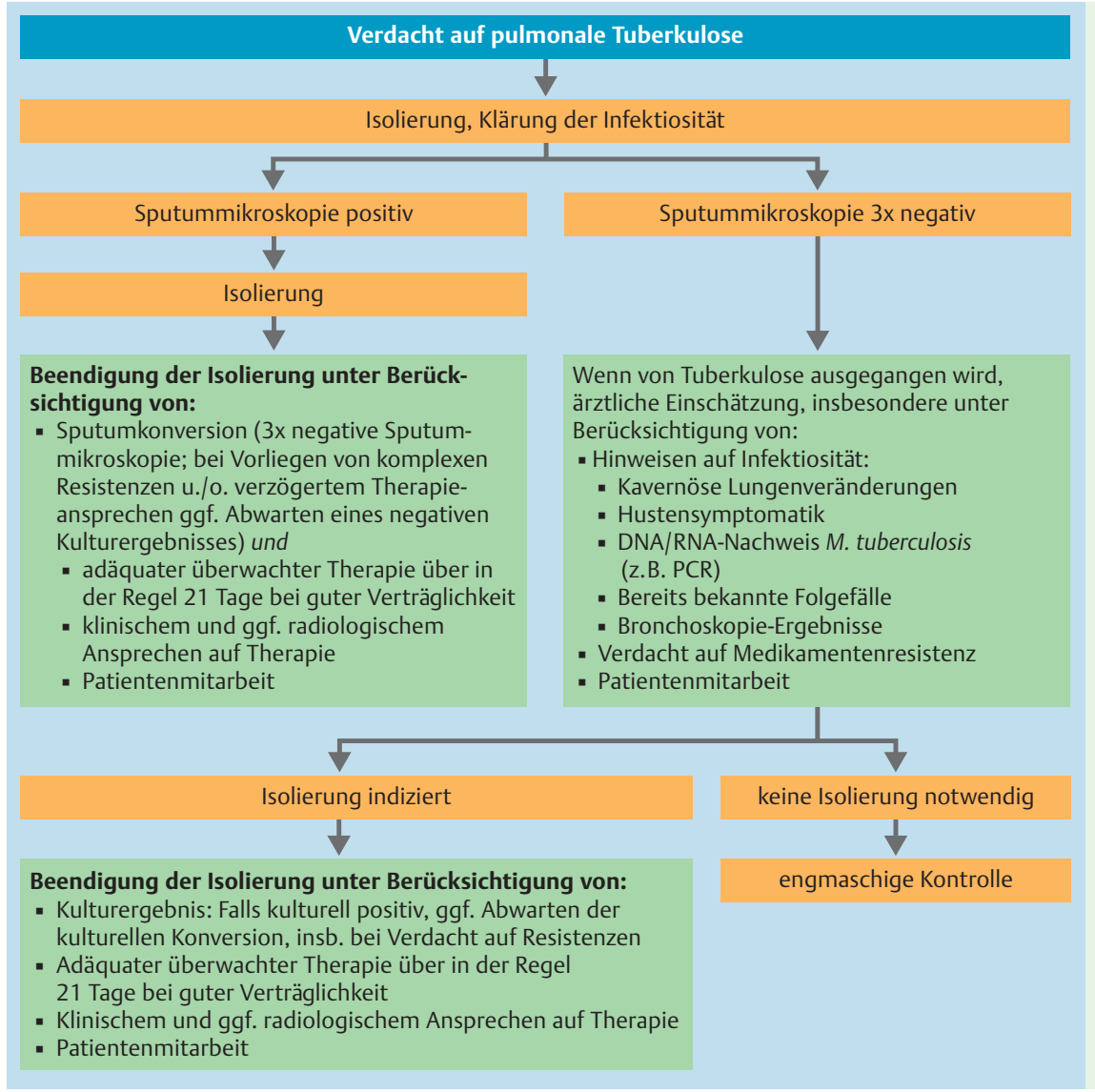

Abb. 1 Algorithmus zur Indikationsstellung der Isolierung bei (potenziell) infektiöser Tuberkulose (als Hilfestellung, kann die individuelle ärztliche Entscheidung nicht ersetzen).

Eine Kohortenisolierung (d.h. Unterbringung im selben Krankenzimmer) von Tuberkulosepatienten kommt wegen der Möglichkeit der Superinfektion in der Regel nicht infrage. Lediglich bei Erkrankung von Personen, bei welchen eine direkte Infektionskette angenommen werden kann (z.B. Mutter-Kind), kann eine Kohortenisolierung erfolgen.

Da HIV-Patienten ein sehr hohes Risiko haben, nach einer Infektion mit Tuberkulosebakterien auch zu erkranken, ist darauf zu achten, dass Tuberkulosepatienten und HIV-Patienten strikt getrennt voneinander untergebracht werden. Auf eine gemeinsame Unterbringung von Tuberkulosepatienten, auch wenn sie nicht mehr als ansteckend eingestuft werden, und immungeschwächten Patienten in einem Zimmer sollte grundsätzlich verzichtet werden.

Solange eine räumliche Isolierung erforderlich ist, sollten Patienten möglichst im Zimmer bleiben. Sie dürfen es zu Spaziergängen auf dem Klinikgelände unter Beachtung besonderer Schutzmaßnahmen (Tragen eines Mund-Nasen-Schutzes) verlassen, vorausgesetzt sie verhalten sich verantwortungsbewusst.

Wichtigstes Ziel der Unterbringung im Einzelzimmer ist, durch die Absonderung des Patienten und durch eine ausreichende Raumlüftung (Verdünnung oder Elimination der infektiösen Aerosole) eine Weiterverbreitung der Erreger in andere Bereiche einer Gemeinschaftseinrichtung/Station zu minimieren.

Um dieses Ziel zu erreichen, werden für Deutschland zwei Möglichkeiten empfohlen:

- Einmal besteht die Möglichkeit der natürlichen Fensterlüf-

tung. Die Abluft muss dabei direkt ins Freie erfolgen, ohne dass eine Gefahr der Erregerübertragung auf andere Bereiche außerhalb des Zimmers besteht. Auf eine häufige Lüftungsfrequenz soll geachtet werden. Die Tür zum Patientenzimmer ist geschlossen zu halten, um eine Verbreitung infektiöser Aerosole in andere Krankenhausbereiche zu verhindern. Zur Vermeidung von unkontrollierten Luftströmen aus dem Patientenzimmer in andere Stationsbereiche kann ein Vorraum sinnvoll sein.

- Die zweite Möglichkeit ist die Verwendung von Raumlufttechnischen Anlagen (RLT-Anlagen). Wenn eine RLT-Anlage vorhanden ist, ist im Patientenzimmer ein Unterdruck einzustellen. Ist ein Vorraum vorhanden, sind zwei Alternativen möglich: Überdruck oder Unterdruck im Vorraum. Bei beiden Lösungen mit Vorraum gelangt keine Luft aus dem Patientenzimmer in den Flur. Auf keinen Fall darf die RLT-Anlage im Isolierzimmer mit Überdruck betrieben werden. Ebenso darf Abluft aus Isolierzimmern nur gefiltert (Schwebstofffilter) in andere Innenbereiche gelangen. Auf eine geeignete Abluftführung ist zu achten. Gelangt die Abluft über eine RLT-Anlage ins Freie, ist keine Filterung erforderlich. Bei Verwendung von RLT-Anlagen muss die Funktion regelmäßig überprüft werden (Zu- und Abluftleistung, Filterintegrität, Strömungsverhältnisse u.a.).

Die Studienlage bezüglich der Effizienz von RLT-Anlagen, welche primär Luftfeuchtigkeit, Temperatur und Frischluftzufuhr in Räumen regeln, in der Prävention der Tuberkulose ist nicht optimal. Mit einer RLT-Anlage allerdings kann unabhängig von saisonalen klimatischen Gegebenheiten eine adäquate Luftwechselrate (12fach/Stunde, entspricht $80 \mathrm{l} / \mathrm{s} /$ Patient bei einem $24 \mathrm{~m}^{3}$ Raum) und eine kontrollierbare Strömungsrichtung erzielt werden [4].

Eine weitere technische Maßnahme der Infektionskontrolle stellt die Desinfektion von Raumluft mittels UV-Licht dar. Der desinfizierende Effekt wird dadurch erreicht, dass die Strahlung durch bestimmte Bereiche der mykobakteriellen DNA absorbiert wird 
und diese zerstört oder an der Vermehrung hindert. Voraussetzung ist ein vertikaler Luftaustausch [84]. Die Effektivität dieser Desinfektionsmaßnahme hängt von der Raumtemperatur, der Luftfeuchtigkeit, der Kontaktzeit der Strahlen mit den Mykobakterien ${ }^{3}$, der Distanz zur UV-Quelle und der Zustandsform der Bakterien ab [15]. Die WHO gibt derzeit Maßnahmen zur Verbesserung der Ventilation gegenüber der Desinfektion von Raumluft mittels UV-Licht den Vorzug [4]. Aufgrund der niedrigen Tuberkulose-Prävalenz und der aktuellen Studienlage zur Wirksamkeit von UV-Licht erscheint eine Empfehlung dieser Maßnahme für Deutschland derzeit nicht gerechtfertigt.

\subsection{Dauer der Isolierung}

Die Dauer der Isolierung von Patienten mit einer ansteckungsfähigen Lungentuberkulose wird in erster Linie von einem mikroskopisch nachweisbaren Rückgang der Erregerausscheidung im Sputum (drei negative Sputen, sofern initial positiv) sowie vom klinischen und ggf. radiologischen Ansprechen auf die Therapie abhängig gemacht. Nukleinsäure-Amplifikationsverfahren sind zur Kontrolle des Therapieverlaufs nicht geeignet, da Nukleinsäuren auch von nicht mehr lebensfähigen Bakterien nachgewiesen werden können. Jede Entscheidung über die Dauer der Isolierung muss individuell getroffen werden.

Die Dauer der Ansteckungsfähigkeit eines Patienten unter einer adäquaten Therapie wird in der Literatur unterschiedlich bewertet $[56,57,59,85-87]$. Grundsätzlich kann - unter adäquater und effektiver Therapie - ein Isolierungszeitraum von 21 Tagen als ausreichend angesehen werden. Bei einem ausgedehnten pulmonalen Befund, insbesondere bei Kavernenbildung, bei initial hoher mikroskopisch nachgewiesener Erregermenge im Sputum oder bei Erkrankungen mit resistenten Tuberkulosestämmen, bei welchen nur schwächer wirksame Antituberkulotika eingesetzt werden können, kann eine Erregerausscheidung deutlich länger bestehen. Zusätzlich sollten bei der Entscheidung über die Aufhebung der Isolierung der Immunstatus des Patienten, die Verträglichkeit der Therapie, die Patientenmitarbeit, das klinische und ggf. radiologische Ansprechen auf die Therapie berücksichtigt werden (siehe $\bullet$ Abb. 1), und es sollte kein Verdacht auf das Vorliegen einer MDR- oder XDR-Tuberkulose (Anamnese, Schnelltest) bestehen. Es ist zu beachten, dass der mikroskopische Nachweis säurefester Stäbchen während einer Therapie nicht immer mit Ansteckungsfähigkeit gleichgesetzt werden kann, da es sich auch um tote, nicht mehr vermehrungsfähige Bakterien handeln kann $[59,88]$.

Falls auf Basis individueller Abschätzung bei Patienten mit ansteckungsfähiger Tuberkulose eine längere Isolierung erfolgte, richtet sich die Beendigung nach dem klinischen und ggf. radiologischen Ansprechen auf die Therapie, der Patientenmitarbeit und ggf. nach den Kulturergebnissen (Abwarten der kulturellen Konversion, falls eine resistente Tuberkulose vorliegt).

Besonders schwierig gestaltet sich die Beurteilung der Ansteckungsfähigkeit resistenter und hier insbesondere der ausschließlich kulturell positiven Tuberkulosen. In diesen Fällen kann es sinnvoll sein, das erste negative Ergebnis der Flüssigkultur abzuwarten, um die Ansteckungsfähigkeit zuverlässig beurteilen zu können und damit die Infektionsgefährdung für die Umgebung bestmöglich zu reduzieren.

\footnotetext{
${ }^{3}$ Bei Verwendung von RLT-Anlagen mit entsprechenden Luftwechselzahlen sind die Kontaktzeiten für eine effektive Desinfektion mit UV-Licht in der Regel zu kurz.
}

Da eine deutliche Reduktion der Erregerausscheidung (und damit Abnahme der Ansteckungsfähigkeit) bereits Tage nach Beginn einer wirksamen Therapie erfolgt, kann nach individueller ärztlicher Abwägung ein entsprechend unterwiesener und kooperativer Patient mit ansteckungsfähiger Tuberkulose das Isolierzimmer für Aufenthalte im Freien auch vor der offiziellen Aufhebung der Isolierung verlassen. Vor dem Verlassen des Isolierzimmers muss der Patient eine Händedesinfektion durchführen und einen Mund-Nasen-Schutz anlegen. Der Weg ins Freie soll direkt und ohne Betreten von Risikobereichen innerhalb der Einrichtung erfolgen.

Bei den nicht ansteckungsfähigen Formen der Lungentuberkulose (geschlossene Tuberkulose) und bei extrapulmonalen Formen ist keine Isolierung notwendig, sofern keine potenziell Aerosol generierenden Handlungen, wie z.B. Spülung eines tuberkulösen Abszesses, vorgenommen werden.

\subsection{Mund-Nasen- und Atemschutz}

Bei Schutzmaßnahmen zur Verminderung des Risikos einer aerogenen Infektion muss zwischen der Abgabe erregerhaltiger Aerosole und der Vermeidung einer Inhalation des kontaminierten Aerosols, vor allem der Tröpfchenkerne, unterschieden werden. Ersteres betrifft den Patienten, das zweite Personal und Besucher. Im Folgenden werden deshalb die unterschiedlichen Arten des Mund-Nasen- bzw. Atemschutzes vorgestellt und deren Gebrauch durch die genannten Personengruppen beschrieben.

Zu den in medizinischen Bereichen eingesetzten Schutzmaßnahmen gehören einerseits der chirurgische Mund-Nasen-Schutz (MNS) und andererseits Atemschutzmasken. Erstere verhindern die Verbreitung von Erregern aus dem Nasen-Rachen-Raum des Trägers, letztere schützen den Träger (beispielsweise medizinisches Personal) vor Aufnahme schädigender Substanzen oder Krankheitserreger aus der Umgebung. Der MNS gilt als Medizinprodukt, für das Leistungsanforderungen mit entsprechenden Prüfverfahren in der DINEN 14683 festgelegt sind. Atemschutzmasken dagegen wurden für den professionellen Arbeitsschutz entwickelt und werden je nach Rückhaltegrad und Gesamtleckage entsprechend den Anforderungen der DINEN 149 in drei definierte Filterklassen eingeteilt (FFP 1 bis 3; FFP: Filtering Face Piece). Entscheidend für die Schutzwirkung ist neben der Dichte des Filtermaterials vor allem die Anpassung an das Gesicht des Trägers und damit der korrekte Sitz. Zur Erleichterung der Atmung werden FFP-Masken auch mit Ausatemventil angeboten. Diese dürfen nur von Personal und Besuchern zum Eigenschutz verwendet werden. Zur Überprüfung der Anpassung an das Gesicht des Trägers stehen qualitative und quantitative Testmethoden des Dichtsitzes zur Verfügung $[89,90]$.

Aufgrund mangelnder wissenschaftlicher Evidenz zur Wirksamkeit der verschiedenen Arten von Atemschutz in der Infektionsprävention der Tuberkulose variieren die Empfehlungen der Fachgesellschaften international erheblich. Im Zusammenwirken mit anderen Maßnahmen (rasche Fallfindung, räumliche Isolierung und schnelle Therapie) gelten sowohl MNS als auch FFPMaske als etablierter Bestandteil des Maßnahmenbündels zur Infektionsprävention bei Tuberkulose.

\subsubsection{Patienten}

Da die Effektivität der Maßnahmen entscheidend von der Kooperation des Patienten abhängt, wird hier nochmals auf den besonderen Stellenwert der individuellen Aufklärung hingewiesen. Der Begriff Hustenetikette beinhaltet einfache Verhaltensmaßnahmen des Patienten mit dem Ziel, die beim Husten freigesetzten 


\begin{tabular}{|c|c|c|}
\hline Art des Schutzes & Tuberkulosepatienten & Personal/Besucher \\
\hline Mund-Nasen-Schutz & $\begin{array}{l}\text { - Außerhalb des Isolierzimmers, um das } \\
\text { abgegebene Aerosol zu reduzieren. } \\
\text { - Innerhalb des Isolierzimmers, wenn } \\
\text { andere Personen anwesend sind. } \\
\text { - Kann solange benutzt werden, wie der } \\
\text { MNS infolge Durchfeuchtung in seiner } \\
\text { Funktion nicht beeinträchtigt ist. }\end{array}$ & \\
\hline $\begin{array}{l}\text { Atemschutzmaske, entspre- } \\
\text { chend den Kriterien einer FFP-2- } \\
\text { Maske nach DIN EN 149, ggf. } \\
\text { mit Ausatemventil }{ }^{1}\end{array}$ & & $\begin{array}{l}\text { Bei Kontakt mit ansteckungs- } \\
\text { fähigen Tuberkulosepatienten und } \\
\text { bei Betreten des Isolierzimmers. }\end{array}$ \\
\hline
\end{tabular}

Tab. 2 Mund-Nasen- und Atemschutz.

1 Es sind FFP-Masken nach DINEN 149 auch in Form eines Mund-Nasen-Schutzes erhältlich.

infektiösen Aerosole zu reduzieren. Sie umfassen: niemanden direkt anhusten, beim Husten Mund und Nase mit einem Papiertuch bedecken, das erregerhaltige Material unmittelbar in bereitgestellte Abfallbehälter entsorgen und anschließend die Hände desinfizieren.

Während des Aufenthaltes im Isolierzimmer tragen Patienten in Abwesenheit anderer Personen keinen MNS.Wenn sich andere Personen (Beschäftigte, Besucher) längere Zeit im Zimmer aufhalten, ist von einer zusätzlichen Sicherheit auszugehen, wenn der Patient - sofern er es toleriert - einen MNS trägt. Bei Verlassen des Isolierzimmers (z. B. wegen notwendiger diagnostischer oder therapeutischer Maßnahmen) ist dagegen das Tragen eines MNS erforderlich und ausreichend.

Ein MNS kann solange benutzt werden, wie er in seiner Funktionsfähigkeit (z.B. wegen Durchfeuchtung) nicht beeinträchtigt ist. Die Entsorgung der mit Erregern kontaminierten MNS erfolgt als infektiöser Abfall in geeigneten Behältern nach AS 180103, die im Patientenzimmer bereitstehen.

\subsubsection{Medizinisches Personal (Beschäftigte)}

Für medizinisches Personal besteht insbesondere dann eine erhöhte Infektionsgefährdung, wenn eine Exposition gegenüber Aerosolen, die durch Hustenstöße eines Patienten mit ansteckungsfähiger Erkrankung freigesetzt werden, nicht vermieden werden kann. Davon ist bei längerem und engem Kontakt zum Patienten im Rahmen körperlicher Untersuchung, bei Maßnahmen, die mit einer erhöhten Aerosolbildung einhergehen (wie Bronchoskopie, Inhalationstherapie, Hustenprovokation, Sputuminduktion, Respiratorbeatmung), bzw. pflegerischen Maßnahmen an unkooperativen Patienten auszugehen. Aerosolbildungen können auch im Rahmen von Autopsien oder in mikrobiologischen Laboratorien bei der Bearbeitung von Patientenmaterial oder Mykobakterienkulturen entstehen. Hinsichtlich weiterer Details der Infektionsverhütung in mykobakteriologischen Laboratorien sei an dieser Stelle auf die Fachliteratur verwiesen [91].

Abweichend von den bisherigen Empfehlungen ist das Schema der respiratorischen Schutzmaßnahmen vereinheitlicht worden. Für medizinisches Personal wird generell bei der Versorgung ansteckungsfähiger Tuberkulosepatienten das Tragen eines Atemschutzes, der die Kriterien einer FFP-2-Maske nach DINEN 149 erfüllt, empfohlen (siehe Tab.2). Gleiches gilt für nicht-medizinisches Personal, das sich im Isolierzimmer aufhält (z. B. Reinigungspersonal, Techniker). In speziellen Situationen mit potenziell hoher Aerosolexposition muss eine gesonderte Gefährdungsbeurteilung zur Entscheidung über den geeigneten Atemschutz erfolgen.
Da die Effizienz des Atemschutzes entscheidend von dem passgerechten Anlegen und dem korrekten Tragen abhängt, ist die Auswahl der Atemschutzmasken insbesondere bei Bartträgern sehr sorgfältig zu treffen und zu überprüfen, ggf. sollte ein Fit-Test $[89,90]$ durchgeführt werden.

Eine FFP-Maske kann von derselben Person über einen längeren Zeitraum auch in der Versorgung mehrerer Tuberkulosepatienten getragen werden, wenn sie nicht beschädigt, verschmutzt oder durchfeuchtet ist. In der benutzungsfreien Zeit können Masken außerhalb des Isolierzimmers, geschützt vor Verschmutzung und Durchfeuchtung, gelagert werden. Experimentell konnte gezeigt werden, dass von Atemschutzmasken in der Regel kein Infektionsrisiko ausgeht, sie stellen kein Reservoir für M. tuberculosis dar, von dem Erreger wieder in die Luft freigesetzt werden können. Dementsprechend können sie mit dem normalen Krankenhausabfall entsorgt werden [92].

\subsubsection{Besucher}

Für Besucher wird für den Aufenthalt im Patientenzimmer ebenfalls ein Atemschutz, der die Kriterien einer FFP-2-Maske nach DINEN 149 erfüllt, empfohlen. Unbedingt notwendig ist es, Besucher in die korrekte Benutzung des Atemschutzes einzuweisen. Aus Sicht der Infektionsverhütung ist die Zahl der Besucher möglichst einzuschränken.

\subsection{Schutzkittel und Schutzhandschuhe}

Wenn die Gefahr einer Kontamination mit erregerhaltigem Material besteht, sind - gemäß der Standardhygiene - Schutzkittel ${ }^{4}$ und Schutzhandschuhe zu tragen. Dies ist insbesondere der Fall

- bei engem Kontakt mit einem infektiösen Patienten,

- bei der Gefahr einer Aerosolbildung z.B. bei Bronchoskopien, endotrachealem Absaugen, Sputuminduktion, In- und Extubation.

Für Tätigkeiten mit hoher Wahrscheinlichkeit für eine Kontamination kann ein Einwegkittel verwendet werden, der nach Gebrauch entsorgt wird. Bei geringer Wahrscheinlichkeit einer Kontamination kann ein Mehrwegkittel getragen werden, der nach Benutzung, sofern er nicht kontaminiert wurde, hängend im Vorraum bzw. außerhalb des Patientenzimmers aufbewahrt wird und einmal pro Schicht gewechselt wird. Dieser patientenbezogene Schutzkittel wird über der normalen Dienstkleidung getragen und vor/nach jedem Patientenkontakt an-/ausgezogen. Im Falle einer Kontamination wird der Mehrwegkittel in Wäschesäcken, die im Patientenzimmer bzw. im Vorraum verschlossen werden, entsorgt (s.u.). Bei Verrichtungen ohne direkten Patien-

\footnotetext{
${ }^{4}$ Hierbei handelt sich nicht um den üblichen Arztkittel, sondern um einen spezifischen Schutzkittel, der am Rücken zu verschließen ist.
} 
Tab.3 Maßnahmen zur Prävention der Tuberkuloseübertragung.

\begin{tabular}{|c|c|c|c|c|c|c|}
\hline Art der Erkrankung & $\begin{array}{l}\text { Infektionsweg } \\
\text { (infektiöses Material) }\end{array}$ & $\begin{array}{l}\text { Räumliche } \\
\text { Isolierung }\end{array}$ & $\begin{array}{l}\text { Atem- } \\
\text { schutz }\end{array}$ & $\begin{array}{l}\text { Schutz- } \\
\text { kittel }\end{array}$ & $\begin{array}{l}\text { Schutzhandschuhe/ } \\
\text { Händehygiene }\end{array}$ & $\begin{array}{l}\text { Dauer der } \\
\text { Maßnahmen }\end{array}$ \\
\hline \multicolumn{7}{|l|}{ Lungentuberkulose } \\
\hline infektiös & $\begin{array}{l}\text { Inhalation erregerhaltiger } \\
\text { Tröpfchen/Aerosol (z. B. } \\
\text { Sputum, Bronchialsekret) }\end{array}$ & ja & ja & $\mathrm{ja}^{1}$ & $\mathrm{ja}^{1}$ & siehe Abb. 1 \\
\hline nicht infektiös & & nein & nein & nein & nein & \\
\hline \multicolumn{7}{|c|}{ Extrapulmonale Tuberkulose } \\
\hline $\begin{array}{l}\text { Absonderung } \\
\text { (z.B. perforierter } \\
\text { Lymphknoten) }\end{array}$ & Sekret/Eiter & nein $^{2}$ & nein* & $\begin{array}{l}\text { ja }^{1} \text { (z. B. } \\
\text { Verbands- } \\
\text { wechsel) }\end{array}$ & $\mathrm{ja}^{1}$ & $\begin{array}{l}\text { solange Sekret } \\
\text { oder Eiter } \\
\text { nachweisbar }\end{array}$ \\
\hline Urogenitaltuberkulose & $\begin{array}{l}\text { Urin/Prostatasekret/ } \\
\text { Menstrualblut }\end{array}$ & nein $^{2,3}$ & nein* & nein $^{1}$ & nein $^{1}$ & $\begin{array}{l}\text { solange } \\
\text { mikroskopisch } \\
\text { positiv }\end{array}$ \\
\hline Meningitis & - & nein & nein & nein & $\begin{array}{l}\text { nur bei Liquor- } \\
\text { punktion }\end{array}$ & \\
\hline
\end{tabular}

${ }^{1}$ nur notwendig bei (erwartetem) Kontakt mit erregerhaltigem Material.

${ }^{2}$ Einzelzimmer bei nicht kooperativen Patienten, ggf. bei Kindern, empfohlen.

${ }^{3}$ bevorzugt eigene Toilette, bei Inkontinenz evtl. räumliche Isolierung.

* sofern nicht im Einzelfall durch ärztliche Eingriffe (z. B. Aerosol erzeugender Eingriff) bzw. durch pflegerische Maßnahmen (z. B. Verbandwechsel bei großflächigen Wunden) eine Übertragung für möglich gehalten wird.

tenkontakt, bei denen eine Kontamination so gut wie ausgeschlossen ist, ist kein Schutzkittel erforderlich.

Auf die Notwendigkeit der hygienischen Händedesinfektion auch bei der Verwendung von Handschuhen wird explizit hingewiesen.

Eine Zusammenfassung der Hygienemaßnahmen gibt $\bullet$ Tab.3 wieder.

\subsection{Desinfektionsmaßnahmen}

\subsubsection{Flächendesinfektion}

Eine von kontaminierten Flächen ausgehende aerogene Infektionsgefährdung wird als sehr gering eingestuft, da sedimentierte Partikel praktisch nicht als lungengängige Tröpfchenkerne erneut in die Luft freigesetzt werden. Deswegen unterscheidet sich die Reinigung und Desinfektion zunächst nicht von der sonst im Krankenhaus üblichen [93]. Nach Kontamination mit erregerhaltigem Material ist eine sofortige gezielte Desinfektion mit einem Mittel mit nachgewiesener Wirkung auch auf Mykobakterien durchzuführen [46]. Entsprechend der Standardhygiene sind patientennahe Flächen täglich desinfizierend zu reinigen. Nach Entlassung/Verlegung des Patienten mit ansteckungsfähiger Tuberkulose wird eine Wischdesinfektion im Patientenzimmer durchgeführt. Dabei sind Flächendesinfektionsmittel mit geprüfter Wirksamkeit auf Mykobakterien zu verwenden und die vom Hersteller empfohlenen Einwirkzeiten einzuhalten. Eine Raumdesinfektion, bei der Flächendesinfektionsmittel in die Raumluft versprüht wird, oder eine Formalin-Verdampfung ist nicht erforderlich.

\subsubsection{Medizinprodukte ${ }^{5}$}

Die Aufbereitung von Medizinprodukten erfolgt gemäß der einheitlichen Standards [94].

\footnotetext{
${ }^{5}$ Medizinprodukte sind Instrumente, Apparate, und Stoffe, die für medizinische Zwecke, wie die Erkennung, Verhütung, Überwachung, Behandlung oder Linderung von Krankheiten, bestimmt sind und deren Hauptwirkung im oder am menschlichen Körper - im Gegensatz zu den Arzneimitteln nicht auf pharmakologischem, immunologischem oder metabolischem Weg erreicht wird. Für eine exakte Definition siehe §3 des Medizinproduktegesetzes [95].
}

\subsection{Entsorgung}

Mit erregerhaltigem Material (Sputum, ggf. Wundsekret) kontaminierte Abfälle sind als infektiöse Abfälle gesondert in geeigneten Behältern zu sammeln und nach der Abfallschlüsselnummer AS 180103 der Abfallverzeichnis-Verordnung zu entsorgen (z.B. Papiertaschentücher zum Auffangen von Sputum, Mund-NasenSchutz von Patienten, Endotrachealtuben, Sputum-Einmal-Becher, Verbandsmaterialien, Einweg-Schutzkittel, Handschuhe) [96]. Dazu sollen die Behälter für die Sammlung von infektiösem Abfall im Zimmer bereitstehen. Die Entsorgung erfolgt gemäß den örtlichen Regeln für die Entsorgung von infektiösem Abfall. Atemschutz von Personal und Besuchern gilt nicht als infektiöser Abfall und kann mit dem normalen Krankenhausabfall (AS 180104) entsorgt werden.

Mit erregerhaltigem Material kontaminierte Wäsche der Patienten und kontaminierte Schutzkleidung des Personals wird im Patientenzimmer in Wäschesäcke abgegeben. Diese werden im Zimmer verschlossen. Die Wäsche muss in einem chemothermisch desinfizierenden Waschverfahren aufbereitet werden, das heißt, dass klinikübliche Waschverfahren ausreichend sind. Eigene Patientenkleidung kann in einer verschlossenen Plastiktüte auf direktem Weg nach Hause mitgenommen werden und sollte dort bei mindestens $60^{\circ} \mathrm{C}$ mit einem handelsüblichen Vollwaschmittel gewaschen werden.

Benutztes Geschirr kann in Geschirrspülmaschinen $\left(\geq 60^{\circ} \mathrm{C}\right)$ auf der Station oder in einer entsprechenden zentralen Anlage ohne besonderen Zusatzaufwand zusammen mit anderem Geschirr gereinigt werden. Aus infektionspräventiver Sicht besteht kein Anlass zur Verwendung von Einweggeschirr.

Ausscheidungen (Urin, Stuhl) können ohne vorherige Desinfektion der Kanalisation zugeführt werden, eine Infektionsgefahr für die Öffentlichkeit besteht dadurch nicht. Wie üblich sollen für die Entsorgung von Ausscheidungen und die Aufbereitung von Pflegegeschirr (Steckbecken etc.) Reinigungs- und Desinfektionsgeräte (RDG) zum Einsatz kommen.

Auch Gefäße zum Sammeln von Sputum oder Absauggefäße können in einem RDG thermisch gereinigt und desinfiziert werden. Durch die automatische Entleerung dieser Gefäße in den Maschi- 
nen wird im Gegensatz zu manuellem Ausschütten der Aerosolkontakt für das Personal verhindert.

5.7 Maßnahmen bei an Tuberkulose erkrankten Kindern An pulmonaler Tuberkulose erkrankte Kinder unter 10 Jahren gelten in der Regel als nicht ansteckend [97]. Sie weisen seltener Kavernen auf, husten weniger und scheiden weniger Erreger aus $[98,99]$.

Die Ergebnisse der mikroskopischen und kulturellen Untersuchung (von Sputum und/oder Magensaft) können wie beim Erwachsenen zur individuellen Einschätzung der Ansteckungsfähigkeit herangezogen werden. Jugendliche, die Sputum produzieren können, unterscheiden sich hinsichtlich Infektiosität nicht von Erwachsenen (siehe $\bullet$ Abb. 1). Ist eine Ansteckungsfähigkeit gegeben, entsprechen die Kriterien zur Beurteilung der Dauer der Isolierung denjenigen für erwachsene Tuberkulosepatienten (siehe $\odot$ Abb. 1).

Eine Isolierung, sofern notwendig, kann gemeinsam mit den Eltern (bzw. einer Bezugsperson) erfolgen. Falls die Eltern selbst nicht infiziert bzw. erkrankt sind, sollte auf entsprechende Maßnahmen der Infektionsverhütung geachtet werden.

\section{Maßnahmen im ambulanten medizinischen Bereich (Praxen) \\ $\nabla$}

Wenn tuberkuloseverdächtige bzw. ansteckungsfähige Patienten ambulant diagnostiziert oder behandelt werden, gelten dieselben Anforderungen wie bei stationärem Aufenthalt.

Über die Standardhygiene hinaus ist in der ambulanten Praxis Folgendes zu beachten: Patienten mit Verdacht auf aktive Tuberkulose oder Patienten mit noch ansteckungsfähiger Tuberkulose, die sich in ambulanter Behandlung befinden, werden zu Beginn oder am Ende der Sprechstunde einbestellt, halten sich am besten in einem separaten Raum auf, beachten die Hustenetikette und tragen einen geeigneten Mund-Nasen-Schutz. Das Personal muss sich vor Hustenstößen des Patienten und bei infektionsgefährdenden Untersuchungen vor Aerosolübertragungen mit einem Atemschutz, der die Kriterien einer FFP-2-Maske nach DIN EN 149 erfüllt, schützen (siehe Kapitel 5.3.2) sowie Schutzhandschuhe und Schutzkittel bei Kontaminationsgefahr tragen (siehe Kapitel 5.4). Kontaminierte Flächen sind desinfizierend zu reinigen, die Aufbereitung von Medizinprodukten erfolgt analog der Aufbereitung im Krankenhaus nach den Vorgaben des Medizinproduktegesetzes.

Wird bei Patienten, bei denen zunächst kein Verdacht bestand, erst im Rahmen der weiteren Abklärung eine Tuberkulose festgestellt, dann sind im Nachhinein für die zurückliegenden Praxisaufenthalte in aller Regel keine Desinfektionsmaßnahmen erforderlich.

\section{Maßnahmen im häuslichen Bereich}

Sofern vom Kranken Erreger ausgeschieden werden, besteht für die engeren Kontaktpersonen das größte Infektionsrisiko vor der Diagnosestellung und vor dem Beginn einer Therapie. Gezielte Maßnahmen können daher erst nach Bekanntwerden der Diagnose erfolgen. Dazu gehören in erster Linie Umgebungsuntersuchungen, die nach erfolgter Meldung vom örtlich zuständigen Gesundheitsamt veranlasst werden [50].
Da Tuberkulosebakterien in aller Regel aerogen übertragen werden, wird das Infektionsrisiko durch potenziell kontaminierte Oberflächen als sehr gering eingeschätzt. In bestimmten Wohnsituationen (Kleinkinder und andere besonders vulnerable Kontaktpersonen, z. B. Immunsupprimierte im Haushalt) können ggf. individuelle Desinfektionsmaßnahmen im Haushalt des ansteckungsfähigen Tuberkulosepatienten angebracht sein. In seltenen begründeten Fällen kann eine Wischdesinfektion von glatten Oberflächen mit einer gegen Tuberkulosebakterien wirksamen Desinfektionsmittellösung erforderlich sein. Stoffoberflächen können, soweit möglich, gewaschen oder chemisch gereinigt werden (Gardinen, Kleidung usw.). Für Teppiche und Teppichböden kommen im Bedarfsfall Sprühextraktionsverfahren in Betracht. Das Versprühen von Formaldehyd ist weder sinnvoll noch zulässig.

Die Entscheidung, ob ein als infektiös erachteter Tuberkulosepatient in der häuslichen Umgebung behandelt werden kann, fällt der Arzt in Zusammenarbeit mit dem Gesundheitsamt und dem Patienten. Solche Patienten sollten kooperativ und in der Lage sein, Grundsätze der Infektionsverhütung eigenverantwortlich und verlässlich umzusetzen. Es sollte darauf geachtet werden, dass die Patienten einen eigenen Schlafraum haben, keine öffentlichen Räume (z.B. Restaurant, Supermarkt) oder Veranstaltungen aufsuchen und keine Reisen unternehmen. Die Räume sollten regelmäßig gelüftet werden.

Um die zur schnellen Minimierung der Ansteckungsfähigkeit notwendige effektive Therapie sicherzustellen, muss die zuverlässige Medikamenteneinnahme gewährleistet sein, ggf. mittels überwachter Therapie. In dem Patientenhaushalt sollten keine Kinder unter fünf Jahren und keine Personen mit immunsuppressiven Erkrankungen oder solche, die immunsuppressive Medikamente einnehmen, leben. Für andere Personen gelten während des infektiösen Stadiums die gleichen Empfehlungen wie für Besucher im Krankenhaus. Infektiöses Sputum kann über die Toilette entsorgt werden. Eine eigene Toilette ist bei Urogenitaltuberkulose nicht erforderlich.

\section{Maßnahmen beim Krankentransport \\ $\nabla$}

Patienten mit infektiöser Lungentuberkulose sollten während des Transports im Krankenwagen einen Mund-Nasen-Schutz tragen [100]. Für das unmittelbar betreuende Sanitätspersonal ist ein Atemschutz, der die Kriterien einer FFP-2-Maske nach DINEN 149 erfüllt, zu empfehlen.

Mit erregerhaltigem Material kontaminierte Flächen müssen gezielt desinfiziert werden. Im Falle einer großflächigen Kontamination durch einen stark hustenden Patienten ohne Mund-Nasen-Schutz ist im Anschluss an den Transport eine Wischdesinfektion aller möglichen Kontaktflächen mit einem geeigneten Flächendesinfektionsmittel mit nachgewiesener Wirkung auch gegen Mykobakterien vorzunehmen. Darüber hinausgehende Desinfektionsmaßnahmen des Transportfahrzeuges sind nicht erforderlich. Grundsätzlich reichen Maßnahmen der Standardhygiene aus.

\section{Maßnahmen in Gemeinschaftseinrichtungen}

$\nabla$

Nach §34 IfSG [78] dürfen Personen mit einer ansteckungsfähigen Lungentuberkulose Gemeinschaftseinrichtungen im Sinne des §33 IfSG (Einrichtungen, in denen überwiegend Säuglinge, 
Kinder oder Jugendliche betreut werden, Kinderkrippen, Kindergärten, Kindertagesstätten, Kinderhorte, Schulen oder sonstige Ausbildungseinrichtungen, Heime, Ferienlager u.ä.) so lange nicht betreten, bis nach ärztlichem Urteil eine Weiterverbreitung der Krankheit durch sie nicht mehr zu befürchten ist. Nach §36 Abs. 4 IfSG müssen Personen, die in ein Altenheim, in eine gleichartige Einrichtung im Sinne des $\S 1$ Abs. 1 oder 1a des Heimgesetzes, in eine im IfSG näher bezeichnete Gemeinschaftsunterkunft oder in eine Erstaufnahmeeinrichtung aufgenommen werden sollen, ein ärztliches Zeugnis vorlegen, dass keine Anhaltspunkte für eine ansteckungsfähige Lungentuberkulose vorhanden sind. Bei Verdacht auf eine ansteckungsfähige Tuberkulose in Gemeinschaftseinrichtungen muss eine sofortige Überweisung zur Diagnosesicherung und weiteren Versorgung des Bewohners erfolgen. Im Falle einer behandlungsbedürftigen Tuberkulose hat die Meldung nach §8 IfSG an das Gesundheitsamt zu erfolgen. Je nach klinischer Symptomatik entscheidet der behandelnde Arzt oder das zuständige Gesundheitsamt, ob desinfizierende Maßnahmen analog zu denjenigen im häuslichen Bereich erforderlich sind. Die zuständige Behörde trifft ihre Entscheidung nach $§ 17$ IfSG. In der Langzeitpflege können Maßnahmen wie im stationären oder ambulanten Bereich notwendig sein (siehe Kapitel 5 und 6).

\section{Maßnahmen in Justizvollzugsanstalten}

$\nabla$

Oft rekrutieren sich Gefangene aus Risikopopulationen mit hoher Tuberkuloseinzidenz bzw. -prävalenz. Die Erkrankung tritt daher unter Inhaftierten häufiger als in der Allgemeinbevölkerung auf $[101,102]$.

Zur effektiven Infektionsverhütung ist die frühe Diagnose einer behandlungsbedürftigen Tuberkulose entscheidend und die aktive Fallfindung unter neu aufgenommenen Inhaftierten sinnvoll [8]. Für die ärztliche Untersuchung einschließlich Thorax-Röntgenuntersuchung als Screening besteht nach $\S 36$ Abs. 4 IfSG Duldungspflicht [78]. Nach $§ 56$ Strafvollzugsgesetz sind die Anstalten zur Sorge für die Gesundheit von Gefangenen verpflichtet und die Gefangenen haben „die notwendigen Maßnahmen zum Gesundheitsschutz und zur Hygiene zu unterstützen“ [103]. Die aktive Fallfindung, die vor der Unterbringung eines neuen Gefangenen in Gemeinschaftsräumen erfolgen sollte [101], minimiert das Risiko, dass Tuberkulose in Gefängnisse eingeschleppt und auf Mitgefangene und Gefängnispersonal übertragen wird [9]. Insbesondere vor deutschlandweiten Überführungen von Gefangenen, die in der Regel über mehrere Haftanstalten mit gemeinschaftlicher Unterbringung erfolgen, sollte eine behandlungsbedürftige Tuberkulose ausgeschlossen werden.

Wenn eine aktive Fallfindung durchgeführt wird und erkannte Tuberkulosefälle einer schnellstmöglichen Behandlung zugeführt werden, ist das Risiko, dass Inhaftierte unerkannt eine infektiöse Lungentuberkulose entwickeln, sehr gering. Da sich im Verlauf der Haft eine latente Tuberkuloseinfektion (LTBI) zu einer behandlungsbedürftigen Tuberkulose weiterentwickeln kann, ist bei entsprechenden Beschwerden eine Tuberkulose differenzialdiagnostisch in Erwägung zu ziehen.

Für Justizvollzugskrankenhäuser gelten die in Kapitel 5 genannten Maßnahmen der Infektionsverhütung gleichermaßen. Wenn die Tuberkulosetherapie eines Inhaftierten initial in einem Zivilkrankenhaus erfolgt, ist im Falle notwendiger Bewachung auf ausreichenden Infektionsschutz beim Bewachungspersonal zu achten.
Vor der gemeinschaftlichen Unterbringung eines bereits anbehandelten Patienten mit pulmonaler Tuberkulose in einer Justizvollzugsanstalt ist besonders sorgfältig eine potenzielle Ansteckungsfähigkeit auszuschließen.

Um die Ausbreitung von Tuberkulose aus Gefängnissen in die Allgemeinbevölkerung zu vermeiden, ist vor Haftentlassung die Fortführung der Therapie in Absprache mit dem zuständigen Gesundheitsamt sicherzustellen.

\section{Interessenkonflikt}

$\nabla$

E. Richter und S. Rüsch-Gerdes geben an, Erstattung von Reisekosten/Teilnahmegebühren für Kongresse oder Fortbildungsveranstaltungen von Unternehmen/Organisationen, die mit in dem Manuskript genannten Produkten/Ergebnissen in Verbindung stehen, sowie zur Evaluation neuer Methoden (finanzielle) Unterstützung von ebensolchen Unternehmen/Organisationen erhalten zu haben. Die übrigen Autoren geben keine Interessenkonflikte im Sinne des ICMJE an.

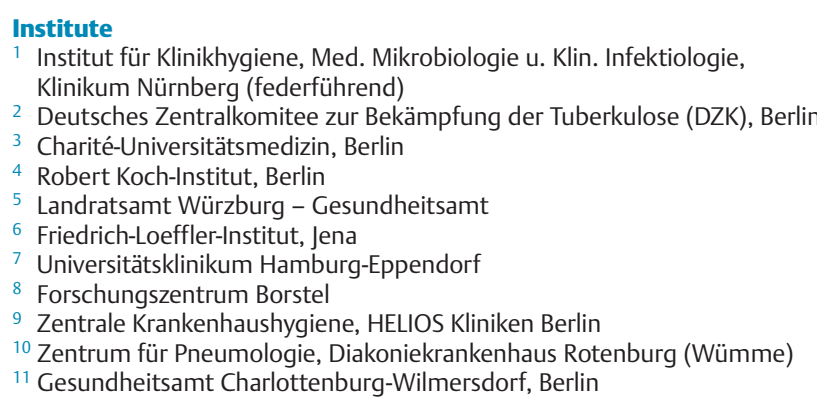

\section{Danksagung}

\section{$\nabla$}

Das DZK dankt dem Bundesministerium für Gesundheit für die Unterstützung. Herrn Dr. S. Dreller von der Deutschen Gesetzlichen Unfallversicherung (DGUV), Abteilung Sicherheit und Gesundheit, Referat „Gesundheitsdienst und Biologische Einwirkungen“, wird für die konstruktiven Anmerkungen gedankt.

\section{Literatur}

1 World Health Organization. Global tuberculosis control: WHO report 2011. Geneva, Switzerland: WHO; WHO/HTM/TB/2011.16

2 Loddenkemper R, Hauer B. Resistente Tuberkulose. Große Herausforderung durch eine Weltepidemie. Dtsch Ärztebl Int 2010; 107: 10 19

3 Nunn P, Reid A, De Cock KM. Tuberculosis and HIV infection: the global setting. J Infect Dis 2007; 196 (Suppl 1): S5 -S14

4 World Health Organization. WHO policy on TB infection control in health-care facilities, congregate settings and households. Genf: 2009: WHO/HTM/TB/2009.419, http://whqlibdoc.who.int/publications/2009/9789241598323_eng.pdf

5 Europäisches Ministerforum der Weltgesundheitsorganisation (WHO). Berliner Deklaration: "All against tuberculosis" am 22. Oktober 2007 in Berlin. http://www.euro.who.int/tuberculosis/TBForum/ 20070621_1 ?language=German

6 Deutsches Zentralkomitee zur Bekämpfung der Tuberkulose. Empfehlungen zur Infektionsverhütung bei Tuberkulose. Frankfurt (Main): pmi-Verlag; 1994

7 World Health Organization. The global MDR-TB \& XDR-TB response plan 2007-2008. Genf: WHO; 2007: WHO/HTM/TB/2007.387

8 World Health Organization. Status Paper on Prisons and Tuberculosis. Copenhagen: World Health Organization Regional Office for Europe; 2007: http://www.euro.who.int/document/e89906.pdf

9 Dara M, Grzemska M, Kimerling ME et al. Tuberculosis Coalition for Technical Assistance and International Committee of the Red Cross. 
Guidelines for control of tuberculosis in prisons. 2009: http://www. tbcta.org//Uploaded_files/Zelf/GuidelineTBPrisons1252321251.pdf

10 Francis J. Curry National Tuberculosis Center. Tuberculosis Infection Control. A practical manual for preventing TB. 2007: http://www.nationaltbcenter.ucsf.edu/TB_IC/docs/ICC_book.pdf

11 U.S. Department of Health and Human Services. Centers for Disease Control and Prevention. Guidelines for Preventing the Transmission of Mycobacterium tuberculosis in Health Care Settings. MMWR; 2005; 54: (No. RR-17)

12 Lungenliga Schweiz. Handbuch Tuberkulose. 2007

13 National Institute for Health and Clinical Excellence. Tuberculosis. Clinical diagnosis and management of tuberculosis, and measures for its prevention and control. Clinical guideline33. UK: 2006

14 Wischnewski N, Mielke M. Prävention der nosokomialen Übertragung der Tuberkulose - Übersicht über verschiedene nationale Empfehlungen. HygMed 2006; 3: 84-92

15 Jost M, Merz B, Rüegger M et al. Tuberkulose am Arbeitsplatz. Gefährdung und Prävention. Dritte vollständig überarbeitete Auflage, Luzern, Schweiz: 2010

16 Robert Koch-Institut. Bericht zur Epidemiologie der Tuberkulose in Deutschland für 2009. Berlin: 2011

17 World Health Organisation. Guidelines for the programmatic management of drug-resistant tuberculosis. Emergency update 2008 Geneva, Switzerland: WHO; 2008: WHO/HTM/TB/2008.402

18 World Health Organization. Towards universal access to diagnosis and treatment of multidrug-resistant and extensively drug-resistant tuberculosis by 2015: WHO progress report 2011. WHO/HTM/TB/ 2011.3

19 World Health Organization. Multidrug and extensively drug-resistant TB (M/XDR-TB). 2010 global report on surveillance and response. WHO/HTM/TB/2010.3

20 World Health Organization. Anti-tuberculosis drug resistance in the world. Report No. 4, 2008: WHO/HTM/TB/2008.394

21 Migliori GB, De Iaco G, Besozzi G et al. First tuberculosis cases in Italy resistant to all tested drugs. Euro Surveill 2007; 12: 3194

22 Menzies D, Joshi R, Pai M. Risk of tuberculosis infection and disease associated with work in health care settings. Int J Tuberc Lung Dis 2007; 11: 593

23 Nienhaus A. Tuberkulose im Gesundheitswesen. Pneumologie 2009; 63: $23-30$

24 Diel R, Seidler A, Nienhaus A et al. Occupational risk of tuberculosis transmission in a low incidence area. Resp Res 2005; 6: 35

25 Menzies D, Fanning A, Yuan $L$ et al. Factors associated with tuberculin conversion in Canadian microbiologiy and pathology workers. Am J Respir Crit Care Med 2003; 167: 599-602

26 Burton JL. Health and safety at necropsy. J Clin Pathol 2003; 56: 254 260

27 Jochem K, Tannenbaum TN, Menzies D. Prevalence of tuberculin skin test reactions among prison workers. Can J Public Health 1997; 88: 202-206

28 De Vries G, van Hest RA. From contact investigation to tuberculosis screening of drug addicts and homeless persons in Rotterdam. European Journal Public Health 2005; 16: 133-136

29 Nardell E, Dharmadhikari A. Turning off the spigot: reducing drug-resistant tuberculosis transmission in resource-limited settings. Int J Tuberc Lung Dis 2010; 14: 1233-1243

30 Nienhaus A, Schablon C, Le Bacle C et al. Evaluation of the interferongamma release assay in healthcare workers. Int Arch Occup Environ Health 2008; 81: 295-300

31 Nienhaus A, Schablon A, Loddenkemper R et al. Erhöhte Prävalenz der latenten tuberkulösen Infektion bei Beschäftigten in der Geriatrie? Pneumologie 2007; 61: 613-617

32 Nienhaus A, Brandenburg S, Teschler H (Hrsg). Tuberkulose als Berufskrankheit. Ein Leitfaden zur Begutachtung und Vorsorge. 2. erweiterte und aktualisierte Auflage. Landsberg: Ecomed Medizin; 2009

33 Panteix G, Gutierrez MC, Boschiroli ML et al. Pulmonary tuberculosis due to Mycobacterium microti: a study of six recent cases in France. J Med Microbiol 2010; 59: 984 -989

34 Une Y, Mori T. Tuberculosis as a zoonosis from a veterinary perspective. Comp Immun Microbiol Infect Dis 2007; 30: 415 - 425

35 Washko RM, Hoefer H, Kiehn TE et al. Mycobacterium tuberculosis infection in a green-winges macaw (Ara chloroptera): report with $\mathrm{Pu}$ blic Health implications. J Clin Mirobiol 1998; 36: 1101-1102
36 Prodinger WM, Eigentler A, Allerberger $F$ et al. Infection of red deer, cattle, and humans with Mycobacterium bovis subsp. caprae in Western Austria. J Clin Microbiol 2002; 40: 2270-2272

37 Schmidt V, Schneider S, Schlömer J et al. Transmission of tuberculosis between men and pet birds: a case report. Avian Pathology 2008; 37: $589-592$

38 Kaneene JB, Miller R, de Kantor IN et al. Tuberculosis in wild animals. Int J Tuberc Lung Dis 2010; 14: 1508 - 1512

39 Zimmermann B, Neßler A, Pöhle D. Tuberkuloseerkrankung: Umgebungsuntersuchung nur beim Menschen? Landesuntersuchungsanstalt (LUA) für das Gesundheits- und Veterinärwesen, Freistaat Sachsen. LUA-Mitteilungen 01/2011

40 Tierseuchengesetz in der Fassung der Bekanntmachung vom 22. Juni 2004. Bundesgesetzblatt; I S. 1260; 3588. 2007

41 Verordnung über anzeigepflichtige Tierseuchen in der Fassung der Bekanntmachung vom 3. November 2004. Bundesgesetzblatt; I S. 2764. 2009

42 Verordnung über meldepflichtige Tierkrankheiten in der Fassung der Bekanntmachung vom 11. Februar 2011. Bundesgesetzblatt; I S. 252. 2011

43 Deppenmeier S, Schieszler A, Nolte I et al. Lungentuberkulose mit Nachweis von Mycobacterium tuberculosis bei einem Golden Retriever. Tierärztliche Praxis 2007; 35: 111 - 115

44 Peters M, Prodinger WM, Gümmer $H$ et al. Mycobacterium tuberculosis infection in a blue-fronted amazon parrot (Amazona aestiva aestiva). Vet Microbiol 2007; 122: 381 - 383

45 Kramer A, Schwebke I, Kampf G. How long do nosocomial pathogens persist on inanimate surfaces. A systematic review. BMC Infectious Diseases 2006; 6: 130

46 Desinfektionsmittel-Kommission im Verbund für Angewandte Hygiene e.V. (VAH). Desinfektionsmittel-Liste des VAH. Wiesbaden: Mhp-Verlag GmbH; 2011

47 Keijmann J, Tjhie J, Olde Damink S et al. Unusual nosocomial transmission of Mycobacterium tuberculosis. Eur J Clin Microbiol Infect Dis 2001; 20: 808-809

48 Hutton MD, Stead WW, Cauthen GM et al. Nosocomial transmission of tuberculosis associated with a draining abscess. J Infect Dis 1990; 161: 286-295

49 Kramer F, Sasse SA, Simms JC et al. Primary cutaneous tuberculosis after a needle-stick injury from a patient with AIDS and undiagnosed tuberculosis. Ann Intern Med 1993; 119: 594-595

50 Diel R, Loytved G, Nienhaus A et al. Neue Empfehlungen für die Umgebungsuntersuchungen bei Tuberkulose. Deutsches Zentralkomitee zur Bekämpfung der Tuberkulose. Pneumologie 2011; 65: 359-378 und Gesundheitswesen 2011; 73: 369-388

51 Riley RL. The contagiosity of tuberculosis. Schweiz Med Wochenschr 1983; 113: $75-79$

52 Sepkowitz KA. How contagious is tuberculosis? Clin Infect Dis 1996; 23: 954-962

53 Behr MA, Warren SA, Salamon $H$ et al. Transmission of Mycobacterium tuberculosis from patients smear-negative for acid-fast bacilli. Lancet 1999; 353: 444-449

54 Bennett DE, Onorato IM, Ellis BA et al. DNA Fingerprinting of Mycobacterium tuberculosis isolates from epidemiologically linked case pairs. Emerg Infect Dis 2002; 8: 1224-1229

55 Hernandez-Garduno E, Cook V, Kunimoto D et al. Transmission of tuberculosis from smear negative patients: a molecular epidemiology study. Thorax 2004; 59: 286-290

56 Long R, Bochar K, Chomyc $S$ et al. Relative versus absolute noncontagiousness of respiratory tuberculosis on treatment. Infect Control Hosp Epidemiol 2003; 24: 831 -838

57 Ritchie SR, Harrison AC, Vaughan RH et al. New recommendations for duration of respiratory isolation based on time to detect Mycobacterium tuberculosis in liquid culture. Eur Respir J 2007; 30: 501 - 507

58 Schwartzman K, Menzies D. Tuberculosis: 11. Nosocomial disease. Canadian Med Ass J 1999; 161: 1271 - 1277

59 Horn DJ, Johnson CO, Oren E et al. How soon should patients with smear-positive tuberculosis be released from inpatient isolation? Infect Control Hosp Epidemiol 2010; 31: 78 - 84

60 Kenyon TA, Valway SE, Ihle WW et al. Transmission of multi-drug resistant Mycobacterium tuberculosis during a long airplane flight. N Engl J Med 1996; 334: 933 - 938

61 Behr MA, Hopewell PC, Paz EA et al. Predictive value of contact investigation for identifying recent transmission of Mycobacterium tuberculosis. Am J Respir Crit Care Med 1998; 158: 465-469 
62 European Centre for Disease Prevention and Control. Risk assessment guidelines for diseases transmitted on aircraft. 2nd ed. Stockholm: ECDC; 2010

63 Robert Koch-Institut. Contact tracing risk assessment profile (CTTAP) for public ground transport. WP/: Contact tracing in ground transport. http://www.rki.de/cln_160/nn_1273968/EN/Content/Prevention/React/Work/WP_7_tool,templateId=raw, property=publicationFile.pdf/WP_7_tool.pdf (Zugriff am 31.5.2011)

64 Haldar $P$, Thuraisingharn $H$, Hoskyns $W$ et al. Contact screening with single-step TIGRA testing and risk of active TB infection: the Leicester cohort analysis. Thorax 2009; 64 (suppl IV): A10

65 Diel $R$, Loddenkemper $R$, Niemann $S$ et al. Negative and positive predictive value of a whole-blood IGRA for developing active TB - an update. Am J Respir Crit Care Med 2011; 183: 88-95

66 Lawn SD, Wood R, Wilkinson RJ. Changing concepts of „latent tuberculosis infection“ in patients with HIV infection. Clin Dev Immunol 2011: DOI 10.1155/2011/980594

67 Marais BJ, Gie RP, Schaaf S et al. Childhood pulmonary tuberculosis. Old wisdom and new challenges. Am J Respir Crit Care Med 2006; 173: 1078 - 1090

68 Diel R, Hauer B, Loddenkemper R et al. Empfehlungen für das Tuberkulose-Screening vor Gabe von TNF-alpha-Inhibitoren bei rheumatischen Erkrankungen. Z Rheumatol 2009; 68: 411 - 416

69 Lin H-H, Ezzati M, Chang H-Yet al. Association between tobacco smoking and active tuberculosis in Taiwan. Am J Respir Crit Care Med 2009; 180: $475-480$

70 Hwang $L Y$, Grimes CZ, Beasley RP et al. Latent tuberculosis infections in hard-to-reach drug using population-detection, prevention and control. Tuberculosis (Edinb) 2009; 89 (Suppl 1): S41 - S45

71 Bellinger O, Götsch U. Tuberkulose-Screening unter Obdachlosen und Drogenabhängigen in Frankfurt am Main. Ein Modell zur Steigerung der Effizienz aktiver Fallfindung. Robert Koch-Institut Epidemiologisches Bulletin 2009; 11: 96-97

72 Rüsch-Gerdes S, Hillemann D. Moderne mykobakteriologische Labordiagnostik. Pneumologie 2008; 62: $533-540$

73 Hillemann $D$, Rüsch-Gerdes $S$, Richter $E$. Feasibility of the GenoType MTBDRsl assay for fluoroquinolone, amikacin-capreomycin, and ethambutol resistance testing of Mycobacterium tuberculosis strains and clinical specimens. J Clin Microbiol 2009; 47: 1767-1772

74 Boehme CC, Nabeta P, Hillemann D et al. Rapid molecular detection of Mycobacterium tuberculosis and rifampicin resistence. N Engl J Med 2010; 363: 1005 - 1015

75 Diel $R$, Goletti D, Ferrara $G$ et al. Interferon- $\gamma$ release assays for the diagnosis of latent Mycobacterium tuberculosis infection: a systematic review and meta-analysis. Eur J Respir 2011; 37: 88 -99

76 Diel $R$, Loddenkemper $R$, Nienhaus A. Evidence based comparison of commercial interferon-gamma release assays for detecting active tuberculosis-a meta-analysis. Chest 2010; 137: 952-968

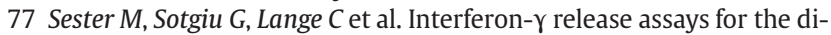
agnosis of active tuberculosis: a systematic review and meta-analysis. Eur J Respir 2011; 37: 100-111

78 Infektionsschutzgesetz. Bonn: Bundesgesetzblatt; Teil 1 G5702, S. 1045. 2000: http://www.gesetze-im-internet.de/ifsg/index.html

79 Forßbohm M, Loytved G, Königstein B (Hrsg.) Handbuch Tuberkulose für Fachkräfte an Gesundheitsämtern. Düsseldorf: Akademie für öffentliches Gesundheitswesen in Düsseldorf; 2009

80 Schaberg T, Bauer T, Castell S et al. Empfehlungen zur Therapie, Chemoprävention und Chemoprophylaxe der Tuberkulose im Erwachsenen- und Kindesalter, (im Druck)

81 Kalsdorf B, Strassburg A, Greinert $U$ et al. Klinik und Diagnose der Tuberkulose. Pneumologie 2008; 62: 284-294

82 Schaberg T, Hauer B. Therapie der Tuberkulose und der latenten tuberkulösen Infektion - Standard für die pulmonalen und die meisten extrapulmonalen Formen. Klinikarzt 2008; 4: 183-188

83 Richter E, Beer J, Diel $R$ et al. MiQ: Mikrobiologisch-infektiologische Qualitätsstandards (MiQ). MIQ 05: Tuberkulose Mykobakteriose, 2. neubearbeitete Auflage, München: Urban \& Fischer; 2010

84 Rudnick SN, First MW. Fundamental factors affecting upper-room ultraviolet germicidal irradiation - Part II. Predicting effectiveness. J Occup Environ Hyg 2007; 4: 352 - 362
85 Fitzwater SP, Caviedes L, Gilman RH et al. Prolonged infectiousness of tuberculosis patients in a directly observed therapy short-course program with standardized therapy. Clin Infect Dis 2010; 51: $371-378$

86 Fortun J, Martin-Davila P, Molina A et al. Sputum conversion among patients with pulmonary tuberculosis: Are there implications for removal of respiratory isolation? J Antimicrob Chemother 2007; 59: $794-798$

$87 \mathrm{Su}$ W-J, Feng J-Y, Chiu Y-C et al. Role of 2-month sputum smears in predicting culture conversion in pulmonary tuberculosis. Eur Respir J 2011; 37: 376-383

88 Kim TC, Blackman RS, Heatwole KM et al. Acid-fast bacilli in sputum smears of patients with pulmonary tuberculosis: prevalence and significance of negative smears pre-treatment and positive smears posttreatment. Am Rev Respir Dis 1984; 129: 264 - 268

89 Coffey CC, Lawrence RB, Zhuang $Z$ et al. Comparison of five methods for fit-testing N95 filtering-facepiece respirators. Appl Occup Environ Hyg 2002; 17: $723-730$

90 Sticher $S$. Individuell angepasster Atemschutz. Sicherheitsingenieur 2011; 6: $28-30$

91 Biostoffverordnung, 58. TRBA 100 Technische Regel für Biologische Arbeitsstoffe des Ausschusses für Biologische Arbeitsstoffe (ABAS). http://www.gesetze-im-internet.de/bundesrecht/biostoffv/gesamt. pdf; http://www.baua.de/de/Themen-von-A-Z/Biologische-Arbeitsstoffe/TRBA/TRBA-100.html

92 Reponen TA, Wang Z, Willeke K et al. Survival of mycobacteria on N95 personal respirators. Infect Control Hosp Epidemiol 1999; 20: 237 241

93 Anforderungen an die Hygiene bei der Reinigung und Desinfektion von Flächen. Empfehlung der Kommission für Krankenhaushygiene und Infektionsprävention beim Robert Koch-Institut (RKI). Bundesgesundheitsbl - Gesundheitsforsch - Gesundheitsschutz 2004; 47: $51-61$

94 Empfehlung der Kommission für Krankenhaushygiene und Infektionsprävention beim Robert Koch-Institut (RKI) und des Bundesinstitutes für Arzneimittel und Medizinprodukte (BfArM) zu den Anforderungen an die Hygiene bei der Aufbereitung von Medizinprodukten. Bundesgesundheitsbl - Gesundheitsforsch - Gesundheitsschutz 2001; 44: $1115-1126$

95 Medizinproduktegesetz in der Fassung der Bekanntmachung vom 7. August 2002 (BGBl. I S. 3146), das zuletzt durch Artikel 12 des Gesetzes vom 24. Juli 2010 (BGBl. I S. 983) geändert worden ist. http:// bundesrecht.juris.de/bundesrecht/mpg/gesamt.pdf

96 Mitteilung der Bund/Länder-Arbeitsgemeinschaft Abfall (LAGA) 18: Vollzugshilfe zur Entsorgung von Abfällen aus Einrichtungen des Gesundheitsdienstes. Stand: 9/2009 www.laga-online.de/laganeu/ images/stories/pdfdoc/veroeffentlichungen/ 18\%20300909\%202.pdf

97 Curtis $A B$, Ridzon $R$, Vogel $R$ et al. Extensive transmission of Mycobacterium tuberculosis from a child. N Engl J Med 1999; 341: 1491 1495

98 Marais BJ, Obihara CC, Warren RM et al. The burden of childhood tuberculosis: a public health perspective. Int J Tuberc Lung Dis 2005; 9: $1305-1313$

99 Magdorf $K$, Bialek $R$, Detjen $A$ et al. Tuberkulose. In: Scholz $\mathrm{H}$, Behoradsky BH, Bialek R, Hrsg. DGPI-Handbuch. Infektionen bei Kindern und Jugendlichen. Deutsche Gesellschaft für Pädiatrische Infektiologie e.V. (DGPI). 5. vollständig überarbeitete Auflage, Stuttgart: Thieme; 2009

100 Mitteilung des RKI zur Infektionsprävention beim Transport von Patienten mit offener Lungentuberkulose. RKI Epidemiologisches Bulletin 2006; 20: 156

101 Groß F. Tuberkulose. In: Keppler K, Stöver H, Hrsg. Gefängnismedizin. Stuttgart: Thieme; 2009

102 Aerts A, Hauer B, Wanlin $M$ et al. Tuberculosis and tuberculosis control in European prisons. Int J Tuberc Lung Dis 2006; 10: 1215 - 1223

103 Gesetz über den Vollzug der Freiheitsstrafe und der freiheitsentziehenden Maßregeln der Besserung und Sicherung (Strafvollzugsgesetz - StVollzG) vom 16. März 1976. Bundesgesetzblatt; I S. 581, 2088. Stand 2009: Bundesgesetzblatt I S. 2274 